\title{
Oncogenic splicing factor SRSF3 regulates ILF3 alternative splicing to promote cancer cell proliferation and transformation
}

\author{
RONG JIA, ${ }^{1,2,4}$ MASAHIKO AJIRO, ${ }^{1,4}$ LULU YU, ${ }^{1,4}$ PHILIP MCCOY JR., ${ }^{3}$ and ZHI-MING ZHENG ${ }^{1}$ \\ ${ }^{1}$ Tumor Virus RNA Biology Section, RNA Biology Laboratory, Center for Cancer Research, National Cancer Institute, National Institutes of Health, \\ Frederick, Maryland 21702, USA \\ ${ }^{2}$ State Key Laboratory Breeding Base of Basic Science of Stomatology (Hubei-MOST) and Ke Laboratory for Oral Biomedicine of Ministry \\ of Education (KLOBM), School and Hospital of Stomatology, Wuhan University, Wuhan, Hubei 430079, China \\ ${ }^{3}$ Flow Cytometry Core Facility, National Heart, Lung, and Blood Institute, National Institutes of Health, Bethesda, Maryland 20892, USA
}

\begin{abstract}
Alternative RNA splicing is an important focus in molecular and clinical oncology. We report here that SRSF3 regulates alternative RNA splicing of interleukin enhancer binding factor 3 (ILF3) and production of this double-strand RNA-binding protein. An increased coexpression of ILF3 isoforms and SRSF3 was found in various types of cancers. ILF3 isoform-1 and isoform-2 promote cell proliferation and transformation. Tumor cells with reduced SRSF3 expression produce aberrant isoform-5 and -7 of ILF3. By binding to RNA sequence motifs, SRSF3 regulates the production of various ILF3 isoforms by exclusion/inclusion of ILF3 exon 18 or by selection of an alternative $3^{\prime}$ splice site within exon 18 . ILF3 isoform-5 and isoform7 suppress tumor cell proliferation and the isoform-7 induces cell apoptosis. Our data indicate that ILF3 isoform-1 and isoform-2 are two critical factors for cell proliferation and transformation. The increased SRSF3 expression in cancer cells plays an important role in maintaining the steady status of ILF3 isoform-1 and isoform-2.
\end{abstract}

Keywords: cancer; ILF3; SRSF3

\section{INTRODUCTION}

Alternative RNA splicing is a principal molecular event for expression of $294 \%$ of all human genes (Zheng 2004; Wang et al. 2008). Regulation of alternative RNA splicing involves interaction between cellular splicing factors and RNA sequences in pre-mRNA (Long and Caceres 2009; Busch and Hertel 2012) and can be easily perturbed by relatively small changes in the levels of splicing factors (Heinzen et al. 2008; Yu et al. 2008). Dysregulated expression of splicing factors interferes with normal RNA splicing of the targeted genes, and the resulting splicing abnormalities lead to aberrant expression of abnormal protein isoforms, consequently causing diseases and tumors (Christofk et al. 2008; Grosso et al. 2008; Cooper et al. 2009; Jia et al. 2010; Dvinge et al. 2016).

Oncogenic SRSF3 (SRp20) is a multifunctional protein and plays a role in transcriptional termination (Cui et al. 2008), posttranscriptional RNA processing (Lou et al. 1998; Cavaloc et al. 1999; Huang et al. 2003; Hautbergue

\footnotetext{
${ }^{4}$ These authors contributed equally to this work as joint first authors. Corresponding author: zhengt@exchange.nih.gov

Article is online at http://www.rnajournal.org/cgi/doi/10.1261/rna. 068619.118.
}

et al. 2008; Ajiro et al. 2016a), protein translation (Bedard et al. 2007), and tumorigenesis (Jia et al. 2010). Through interaction with cis-elements in targeted RNA (Cavaloc et al. 1999; Hargous et al. 2006; Jia et al. 2009; Ajiro et al. 2016a, b), an altered expression level of SRSR3 can change general splicing events essential for proper expression of the targeted mRNAs, leading to either induced cell growth retardation and apoptosis or promotion of cell proliferation, immortalization, and tumorigenesis (Jia et al. 2010; Tang et al. 2013; Ajiro et al. 2016a).

Interleukin enhancer-binding factor 3 (ILF3), also known as CBTF, DRBF, DRBP76, MMP4, MPP4, MPHOSPH4, NF90, NF90a, NF90b, NF110, NF110b, NFAR, NFAR-1, NFAR2, NF-AT-90, TCP80, and TCP110, is a doublestranded RNA binding protein (Duchange et al. 2000; Castella et al. 2015) and is known for its importance in the regulation of cell proliferation and angiogenesis in cancer cells (Vumbaca et al. 2008; Hu et al. 2013; Shamanna et al. 2013). The ILF3 gene in human chromosome 19 encodes a primary transcript with 21 exons (Saunders et al. $2001 \mathrm{a}, \mathrm{b})$ and in mouse chromosome 9 encodes a primary transcript with 22 exons (Buaas et al. 1999), which produces

This is a work of the US Government. 
multiple RNA isoforms by alternative splicing. Among them, ILF3 isoform-1 (NF110/NF110a/NFAR-2/TCP110) and isoform-2 (DRBP76/NF90/NF90a/NFAR-1/NFAR90/ MPP4) are two major splice variants (Duchange et al. 2000; Patiño et al. 2015). The full-length ILF3 (ILF3 isoform-1) contains two double-stranded RNA binding motifs that interact with structured RNA (Barber 2009). Although the exact function of ILF3 remains to be clarified, IIf3 gene knockout mice display growth retardation, muscle degeneration and apoptosis, respiratory failure, and death within $12 \mathrm{~h}$ after birth (Shi et al. 2005). ILF3 was found to play a role in transcription (Reichman and Mathews 2003; Reichman et al. 2003; Shi et al. 2007). Various other studies indicate that ILF3 isoform-2 regulates RNA stability (Kuwano et al. 2008; Pei et al. 2008; Vumbaca et al. 2008) and translation (Kuwano et al. 2008; Pfeifer et al. 2008; Vumbaca et al. 2008), host defense (Urcuqui-Inchima et al. 2006; Pfeifer et al. 2008; Patiño et al. 2015) and cell division (Xu et al. 2003; Shi et al. 2005; Guan et al. 2008).

In this report, we identified by high-throughput RNA splice arrays that cellular ILF3 is a prominent target of SRSF3 in both human and mouse cells. SRSF3 interacts with SRSF3-binding sites in the human ILF3 exon 18 and regulates exclusion of exon 18 to produce ILF3 isoform-1 for NF110 (NFAR2) or inclusion of exon 18 to produce ILF-3 isoform-2 for NF90 (NFAR-1).

\section{RESULTS}

\section{SRSF3 and alternative RNA splicing of interleukin enhancer- binding factor 3 (ILF3)}

We recently reported the genomewide downstream targets of SRSF3 in human U2OS osteosarcoma cells identified by splice array analysis and found interleukin enhancer-binding protein 3 (ILF3) to be one of the major targets of SRSF3 (Ajiro et al. 2016a). Human SRSF3 is identical to mouse Srsf3 (Ayane et al. 1991; Zahler et al. 1992). By inducible expression of T7-tagged human SRSF3 in mouse MEF3T3 cells, the splice array analysis also indicated the altered changes of 134 gene splicing events (65 evidenced and 74 novel splicing events) and 11 gene expression (Supplemental Fig. S1; Supplemental Tables S1S3). We selectively verified by RT-PCR that inducible human SRSF3 regulates alternative splicing of mouse IIf3 (Fig.
1A-C) and Pabpc4 (Fig. 1D). These include production of the increased IIf3 isoform-2 (Fig. 1A), decreased IIf3 isoform-3 (Fig 1A), increased Ilf3 exon 3 skipping (Fig. 1B), and Pabpc4 exon 11 skipping (Fig. 1D). Further characterization of SRSF3-mediated alternative splicing of ILF3 led us to identify six RNA isoforms of mouse IIf3 in MEF3T3 cells (Supplemental Fig. S2A) and seven different RNA isoforms and their corresponding protein isoforms of human ILF3 in U2OS cells (Supplemental Fig. S2B,C). The mouse Ilf3 splicing is mostly conserved with that of human ILF3. Among these isoforms of ILF3, the human ILF3 isoform-7 and -8 identified in U2OS cells and the mouse IIf3 isoform-3L and -3S in MEF3T3 cells are four novel isoforms of ILF3 not reported in other studies (Duchange et al. 2000; Viranaicken et al. 2006). However, the human ILF3 isoform-3 (TCP80) (Xu and Grabowski, 1999; Xu et al. 2003), which is spliced directly from exon 17 to an alternative $3^{\prime}$ splice site within exon 21, was not detectable in our study. Although the inducible human SRSF3 in MEF3T3 cells was found to increase the expression of mouse llf3 isoform-2 (a human ILF3 isoform-2 equivalent), but decrease
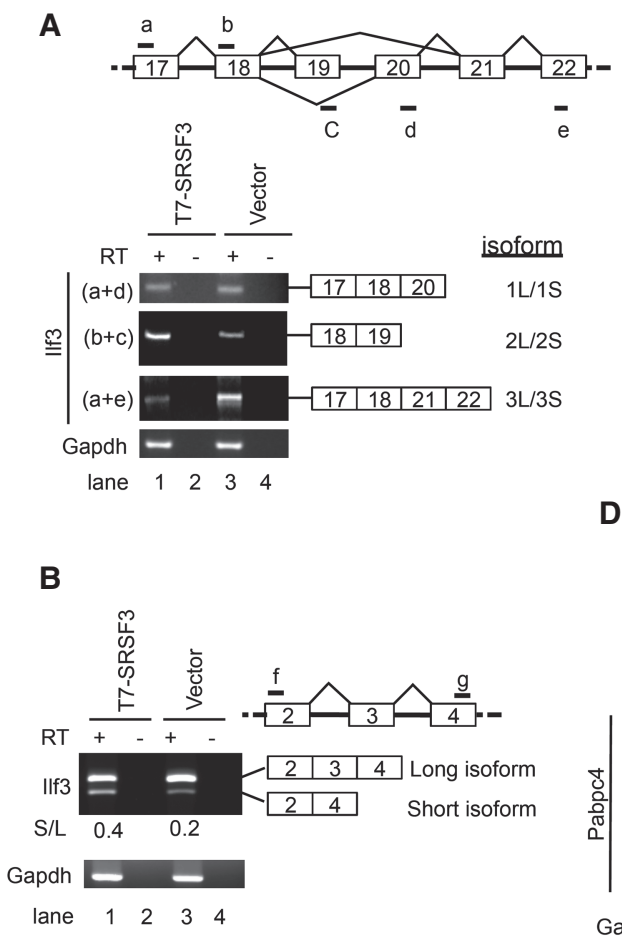

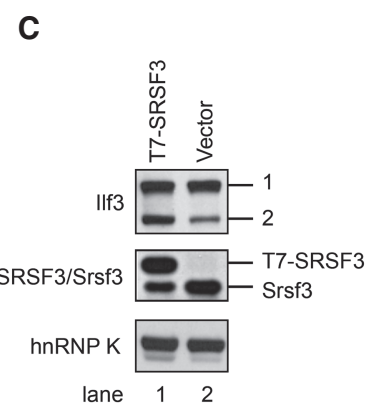

D

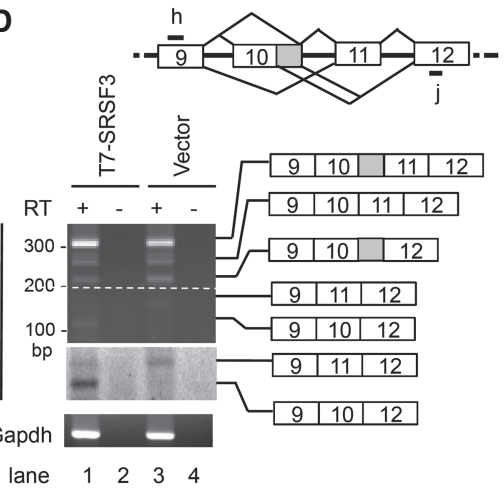

FIGURE 1. Inducible SRSF3 expression regulates alternative RNA splicing of mouse IIf3 and mouse Pabpc4. (A-C) MEF/3T3 cells with inducible expression of T7-SRSF3 were analyzed for IIf3 RNA isoform production by RT-PCR with the primer sets as indicated $(A, B)$ and for protein expression by western blot with corresponding antibodies $(C)$. (D) Detection of alternative RNA splicing of Pabpc4 in MEF/3T3 cells with inducible expression of T7-SRSF3 by RT-PCR. A dashed line in the black gel image shows the same region inverted into white background below to better display a novel spliced product induced in MEF3T3 cells with T7-SRSF3 expression. (+) Plus reverse transcriptase; (-) no reverse transcriptase. Gapdh $(A, B, D)$ served as an RNA loading control, and hnRNP K (C) served as a protein loading control. 
the expression of mouse IIf3 isoform-3 (a human ILF3 isoform-7 equivalent) (Fig. 1A), the inducible human SRSF3 in MEF3T3 cells had little effect on production of mouse Ilf3 isoform-1 (Fig. 1A,C).

\section{SRSF3 regulates the expression of ILF3 isoforms to promote cell proliferation}

In U2OS cells with knockdown of SRSF3 expression, we observed notable changes of alternative RNA splicing of
ILF3 exon 17 to exon 18 or exon 20 from the cells without knockdown of SRSF3 and increased usage of an alternative $3^{\prime}$ splice site within exon 18 (Fig. 2A). The notable changes in alternative RNA splicing led to reduction of ILF3 isoform-1 expression, but increase of ILF3 isolform-7 expressions at protein levels in western blot analysis (Fig. 2B; Supplemental Fig. S2C, compare lane 7 to lanes 5,6, and 8). Subsequently, we confirmed the SRSF3-mediated expression changes in alternative ILF3 RNA splicing in HeLa cells. We demonstrated in both types of cells that

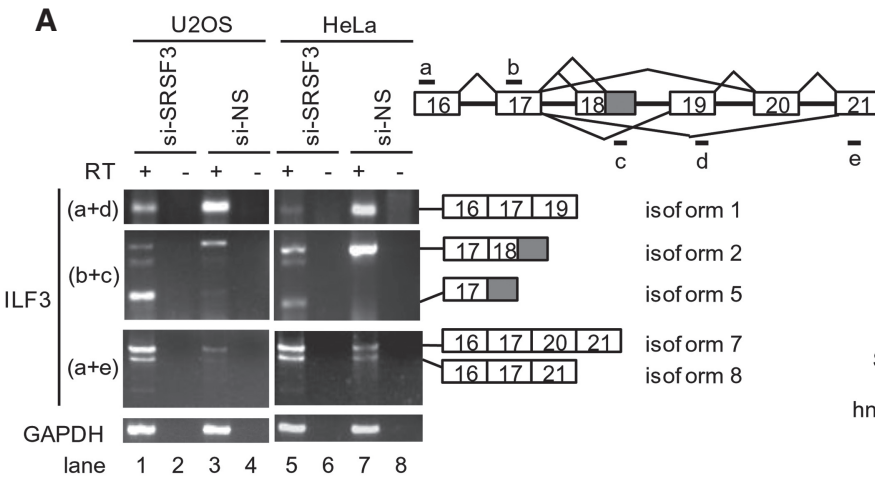

B

C

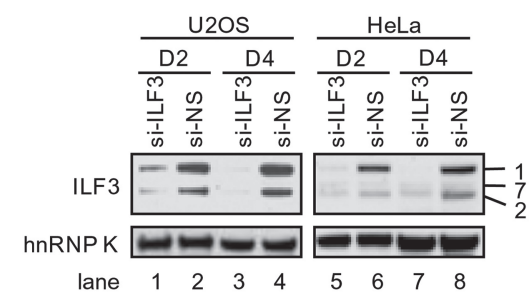

E

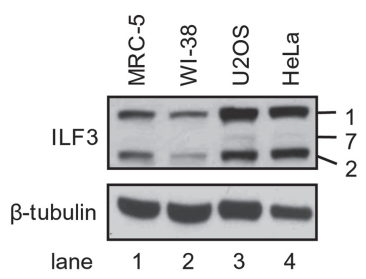

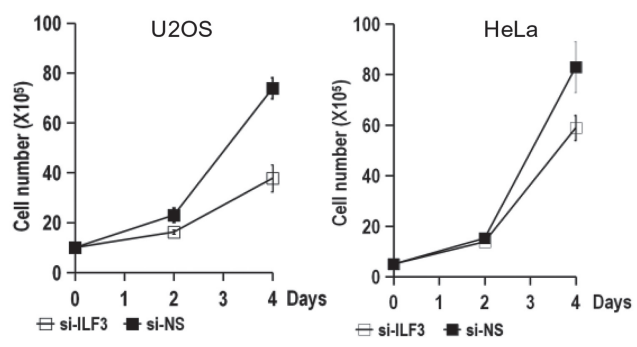

F

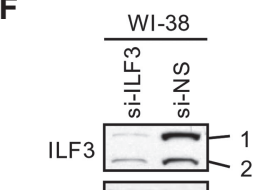

hnRNPK

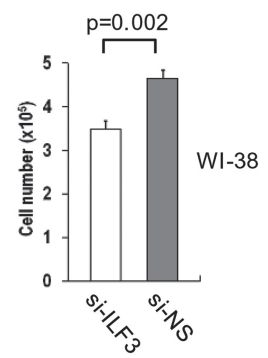

FIGURE 2. SRSF3 regulates alternative RNA splicing and production of ILF3 isoforms to maintain cell growth. (A) Alternative splicing of human ILF3 induced by SRSF3 knockdown in U2OS or HeLa cells was analyzed by RT-PCR. Identities of ILF3 isoforms are indicated on the right. Location of primers (a-e) used for ILF3 isoform detection are shown in the diagram. RT, reverse transcription. (B) Production of ILF3 protein isoforms induced by SRSF3 knockdown in U2OS and HeLa cells. U2OS and HeLa cells were transfected with siRNA (si-SRSF3 or si-NS) for 2 (D2) or 4 (D4) days and analyzed by western blot. hnRNP K served as a sample loading control. (C,D) Knockdown of ILF3 suppresses tumor cell growth. U2OS or HeLa cells were transfected with 40 nM of siRNA (si-ILF3 or si-NS) for 2 (D2) or 4 (D4) days, and the knockdown efficiency of ILF3 by si-ILF3 was confirmed by western blot (C). Cell numbers were counted at D2 and D4 following the first transfection of siRNA (ILF3 for si-ILF3 and NS for si-NS), with mean \pm SE of three replicates (D). (E) Human ILF3 protein expression in MRC-5 and WI-38 (human fibroblast) cells, U2OS (osteosarcoma) cells, and HeLa (cervical cancer) cells by western blot with anti-ILF3 antibody. Cell lysates for blotting SRSF3 in our previous publication (Jia et al. 2010) were reprobed by anti-ILF3 antibody. $\beta$-tubulin served as a sample loading control. (F) Knocking down ILF3 expression in WI-38 cells decreases cell proliferation. WI-38 cells were transfected twice with ILF3 siRNA or NS siRNA at an interval of $48 \mathrm{~h}$ and were counted on day 4. Error bars represent means \pm SE from two independent experiments, each performed in triplicate. The siRNA knockdown efficiency of ILF3 on day 4 was estimated by western blot with an anti-ILF3 antibody and is shown on the left. 
SRSF3 knockdown led to reductions of ILF3 isoform-1 and -2 and inclusion of a partial exon 18 to express ILF3 isoform-5 or exclusion of exons 18-19 or 18-20 to produce ILF3 isoform-7 and -8 (Fig. 2A). The additional band between isoform-2 and isoform- 5 was not a spliced ILF3 product, but derived as heteroduplex DNA molecules containing a single-stranded loop from two RT-PCR products of isoform-2 and isoform-5 during PCR annealing as we reported in other studies (Ajiro et al. 2016b). The regulated ILF3 splicing and isoform production by SRSF3 were independent of SRSF1 although SRSF3 regulates SRSF1 RNA splicing (Ajiro et al. 2016a). Knockdown of SRSF1 expression in U2OS cells had no effect on alternative RNA splicing of ILF3 (Supplemental Fig. S2D,E). SRSF3-regulated ILF3 splicing and isoform production also appeared to be independent of RBM5 and RBM39, two other splicing factors interacting with U2AF proteins (Bechara et al. 2013; Loerch and Kielkopf 2016) and RBM5 having similar RNA-binding motifs to SRSF3 (Ajiro et al. 2016a; Änkö et al. 2012). We found that knockdown of SRSF3 did not affect the expression of both RBM5 and RBM39 (Supplemental Fig. S3A,B), but knocking down RBM5 and RBM39 expression led to a slight reduction of ILF3 isoform-2 (Supplemental Fig. S3C,D).

ILF3 isoform-1 is a full-length protein encoded by the ILF3 gene. Previous studies showed that alternative splicing of ILF3 RNA results in multiple transcript variants encoding distinct protein isoforms (Duchange et al. 2000) that appear to regulate cell division (Xu et al. 2003; Guan et al. 2008). We found that tumor cells, U2OS and HeLa, predominantly express ILF3 isoform-1 and to a lesser extent, ILF3 isoform-2 (Fig. 2B, lanes $2,4,6,8$ ) by western blot analysis. We revealed that the altered ILF3 splicing due to SRSF3 knockdown also led to altered protein expression of the corresponding ILF3 isoforms in both cell types, including the increased protein production of ILF3 isoform 5 and isoform 7 (Fig. 2B, lanes a, 3,5, and 7).

Subsequently, knocking down the expression of both ILF3 isoform-1 and isoform-2 was carried out in U2OS and HeLa cells (Fig. 2C). We found that both isoforms of ILF3 are required for cell proliferation and knockdown of their expression prevents cell proliferation and induces cell growth retardation (Fig. 2D), similar to what we see from published SRSF3 knockdown studies (Jia et al. 2010; Ajiro et al. 2016a). WI-38 and MRC-5 cells, two human diploid lung fibroblast cell lines with a finite lifetime of about 50 population doublings, express naturally less amounts of ILF3 isoform-1 and -2 (Fig. 2E) and also less amounts of SRSF3 than U2OS and HeLa cells (Ajiro et al. 2016a). We found that transient overexpression of SRSF3 in WI-38 cells reduced the expression of ILF3 isoform- 5 RNA, but had no effect on isoform-1 and isoform-2 (Supplemental Fig. S4A). However, knockdown of ILF3 isoform-1 and -2 expressions in WI-38 cells led to a decrease in the proliferation of WI-38 cells (Fig. 2F), consistent with the findings in U2OS and HeLa cells. Altogether, these data suggest that SRSF3 promoting cell proliferation might occur partially through maintaining a physiological level of ILF3 isoform production.

\section{Functional characterization of ILF3 isoform-1, -2, -5, and -7 in cell proliferation and transformation}

Given that the cells described above predominantly express ILF3 isoform-1 and isoform-2, along with little ILF3 isoform-7, but increased to express ILF3 isoform-5, and isoform-7 when SRSF3 levels became deficient, we next examined individual isoforms of ILF3 for their cellular locations and functions in cell proliferation. Fluorescence microscopy studies showed that all examined five ILF3 isoform proteins are nuclear proteins in U2OS cells and appear from small nuclear granules to larger speckles, sometimes even overlapping with nucleoli (Fig. 3). None of them has an inner nuclear membrane preference.

We further transfected WI-38 cells with individual ILF3 isoforms or in combination and subsequently found that introduction of ILF3 isoform-1, -2, or both into WI-38 cells led to increase cell growth (Fig. 4A; Supplemental Fig. S4B). We noticed that the ILF3 isoform-2 appeared to be more potent for promotion of cell proliferation than isoform-1, and transfection of both isoform-1 and isoform-2 showed additive proliferative effects more than that of single ILF3 isoform in WI-38 cells (Fig. 4A). Similarly to WI-38 cells, mouse NIH3T3 cells express little IIf3 (Fig. 4B, lane 2). The human ILF3 isoform-2 promotes more proliferation of $\mathrm{NIH} 3 \mathrm{~T} 3$ cells than ILF3 isoform-1 either by transient (Supplemental Fig. S5A) or by stable transfection (Fig. 4C; Supplemental Fig. S5B). Flow cytometry analysis indicated that the ILF3 isoform-2 increases cell proliferations by enhancing cell cycle progression quickly to the $S$ and $G 2 / M$ phase, but reducing the cells at G0/G1 phase (Supplemental Fig. S6). In contrast, transient expression of ILF3 isoform-1 and -2 into the U2OS cells, which already express higher amounts of ILF3 isoform-1 and -2 (Fig. 2E), did not show any effect on U2OS cell proliferation (Supplemental Fig. S5C). However, knockdown of SRSF3 expression in $\mathrm{U} 2 \mathrm{OS}$ cells led to a reduction in the expression of ILF3 isoform-1 and isoform-2 (Fig. 2A,B) and severely blocked cell proliferation (Jia et al. 2010). We found that this inhibition of U2OS cell proliferation due to SRSF3 deficiency could be partially rescued by overexpression of ILF3 isoform 2 (Fig. 4D,E).

Stable repression of the ILF3 isoform-2 has been shown to reduce tumorigenic potential in an orthotopic breast tumor model (Vumbaca et al. 2008). Subsequently, we examined the cell transformation potentials of the human ILF3 isoform- 1 and -2 in NIH3T3 cells. The stable expression of human ILF3 isoform-1 and -2 in the presence of endogenous Ilf3 isoforms (Fig. 4B) was found to promote cell colony formation in soft agar (Fig. 4F) in addition to promoting 


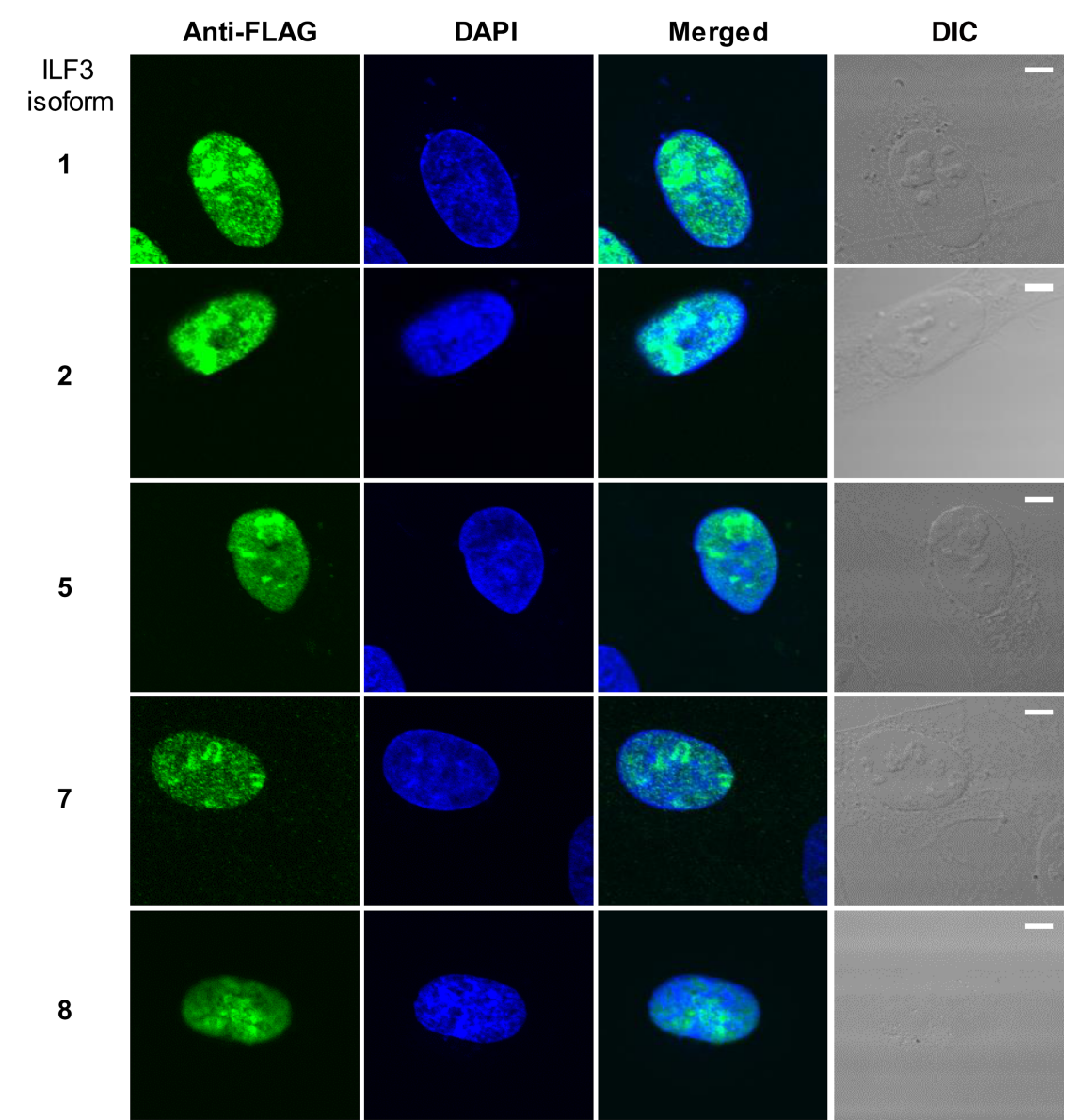

FIGURE 3. Nuclear localization of ILF3 isoforms in U2OS cells. U2OS cells transfected with a Myc/Flag expression vector pCMV6-ILF3 (isoform-1), pJR19 (isoform-2), pJR18 (isoform-5), pJR16 (isoform-7), or pJR15 (isoform-8) were stained with an anti-Flag antibody and imaged by immunofluorescent microscopy. The nucleus was stained with DAPI. A fluorescence image, a DAPI nuclear staining image, a merged fluorescence-DAPI image, and a differential interference contrast (DIC) image are presented for each ILF3 isoform expression in the cells. Scale bar, $5 \mu \mathrm{m}$.

cell growth (Fig. 4C; Supplemental Fig. S5B). The ILF3 isoform-2 in stable expression produced more and even larger colonies than that of ILF3 isoform-1, despite both isoforms showing transformation potency (Fig. 4F). Altogether, these data indicate that regulation of ILF3 isoform production is one of the mechanisms by which SRSF3 promotes cell proliferation and tumorigenesis.

Considering that U2OS and HeLa cells can be easily induced to express the ILF3 isoform- 5 and -7 by knockdown of SRSF3 expression (Fig. 2A,B), we next transfected U2OS cells with ILF3 isoform-5 or isoform-7 in the presence of endogenous ILF3 isoform-1 and -2. Both ectopic ILF3 isoform -5 and -7 individually exhibited suppressive effects on cell growth and even more growth inhibition by coexpression (Fig. 4G). In NIH3T3 cells, ectopic ILF3 isoform7, either by transient transfection or by stable transfection, exerted the same suppressive effect on cell growth (Supplemental Fig. S5A,B) as seen for U2OS cells (Fig. 4G), but the ILF3 isoform-5 at transient transfection lacks this negative function in NIH 3T3 cells (Supplemental Fig. S5A) and instead, even induced cell proliferation by stable transfection to NIH3T3 cells (Supplemental Fig. S5B). This discrepancy of the isoform-5 on the cell growth from $\mathrm{NIH} 3 \mathrm{~T} 3$ to U2OS cells remains to be understood. To investigate the mechanism by which ILF3 isoform- 5 and -7 function as a cell growth inhibitor, $\mathrm{U} 2 \mathrm{OS}$ cells with transient transfection of individual ILF3 isoforms were blotted for poly(ADP-ribose) polymerase (PARP) cleavage as an apoptosis marker (Tewari et al. 1995; Majerciak et al. 2010). We found that expression of ILF3 isoform-7, but not isoform-5, induced apoptotic cleavage of PARP in U2OS cells (Fig. 4H). This result is consistent with SRSF3 knockdown-induction of PARP cleavage (Jia et al. 2010) and of ILF3 isoform-7 production (Fig. 2A,B). Data indicate that the ILF3 isoform-7 blocks cell proliferation by induction of cell apoptosis, whereas the functions of ILF3 isoform-1 and -2 promote cell growth.

\section{Increased coexpression of ILF3 isoform-2 and SRSF3 in multiple types of cancer tissues}

Having demonstrated that SRSF3 regulates ILF3 RNA splicing and that ILF3 isoform-1 and -2 are needed for cell proliferation, we further analyzed tumor tissues for increased expression of ILF3 isoforms. RNA-seq analysis of normal and diseased cervical tissues showed the increased ILF3 RNA expression remarkably in cervical intraepithelial neoplasia (precancer) lesions and cervical cancer tissues over the normal cervical tissues (Fig. 5A). By western blot analyses of paired normal and cancer tissues, we found that increased expression of ILF3 isoform-2 and sometimes also ILF3 isoform-1 in tumor tissues from cervix, thyroid, breast, stomach, skin, and bladder was always associated with higher levels of expression of SRSF3 than that seen in the corresponding normal tissues (compare lanes $1,3,5,7$, and 9 to lanes $2,4,6,8$, and 10 both in Fig. 5B,C). ILF3 isoform-7 was under the detection level in all of these tissues (Fig. 5B,C).

By searching the Oncomine cancer microarray database (https://www.oncomine.org), we found much higher expression $(1.59$-fold, $P<0.05)$ of ILF3 in tumor tissues than 
that seen in their corresponding normal tissues in 137 of 227 paired studies. Fisher's meta-analysis indicates that the observed ILF3 increase in tumor tissues among those
A

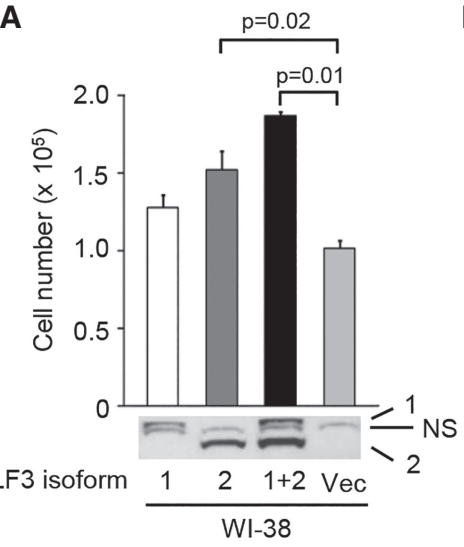

B

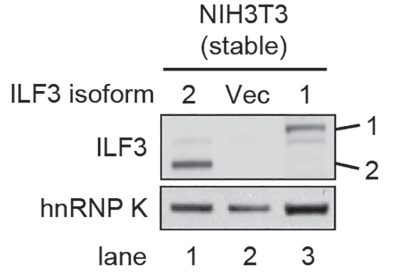

C

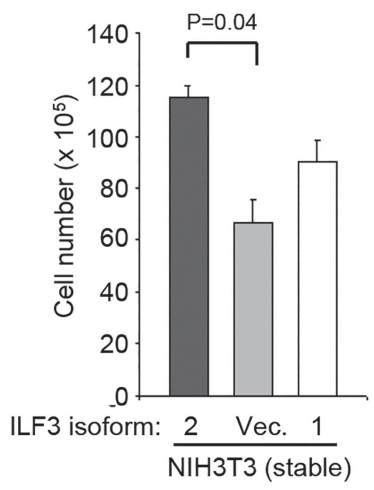

D

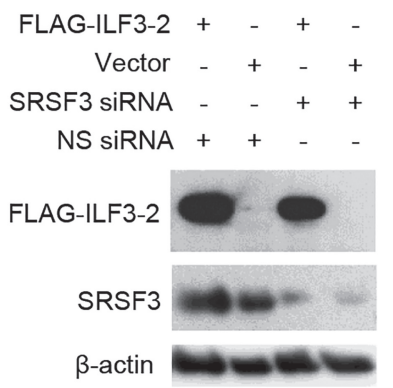

E

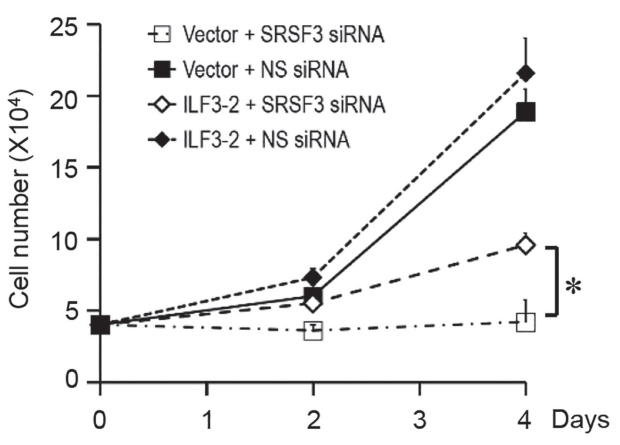

$\mathbf{F}$

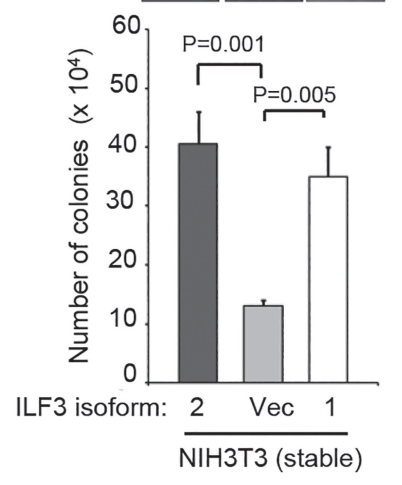

G

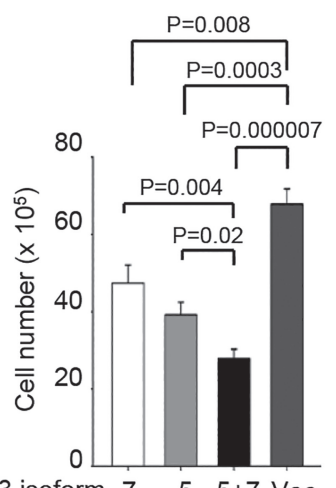

ILF3 isoform $7 \quad 5 \quad 5+7 \mathrm{Vec}$

H

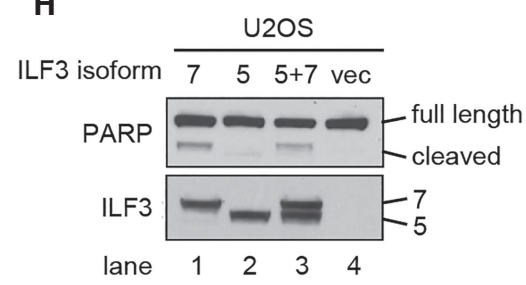

FIGURE 4. (Legend on next page) paired studies was significant $\left(P<1 \times 10^{-290}\right)$. Further analysis of the paired studies with increased SRSF3 and ILF3 coexpression also found that the increased ILF3 isoform2 is mostly in close correlation with the increased expression of SRSF3 ( $P$ $<0.05)$ in 57 of 89 studies. Among 32 breast cancer studies with available clinical pathology data, 17 studies showed higher expression $(P<$ 0.05 ) of ILF3 isoform-2 in high-grade tumors than in low-grade tumors, with a result of $P=2.16 \times 10^{-23}$ in Fisher's meta-analysis, indicating a close correlation between ILF3 isoform-2 expression and tumor progression. In the majority of glioblastoma (Sun et al. 2006) and melanoma (Talantov et al. 2005) tissues (Fig. 5DF), a higher level of ILF3 isoform-2 expression was almost always associated with an increased level of SRSF3 expression, with only a few exceptions. Collectively, the data provide further evidence of increased coexpression of SRSF3 and ILF3 isoform-2 in cancer tissues.

\section{SRSF3 interacts with ILF3 RNA and binds to the ILF3 exon 18}

To characterize the mechanism by which SRSF3 regulates the inclusion/ skipping of exon 18 and exon 19 of ILF3, we initially searched for the potential SRSF3-binding motifs and ACrich sequences in the ILF3 exon 18 in a size of $1351 \mathrm{nt}$ and exon 19 in a size of $362 \mathrm{nt}$ by using the SFmap version 1.8 (http://sfmap.technion.ac.il/) (Akerman et al. 2009; Paz et al. 2010) based on SELEX motifs (systematic evolution of ligands by an exponential enrichment motif). The AC-rich sequence has been characterized as a binding motif of SRSF3 and hnRNP L in HPV16 and other transcripts (Hui et al. 2005; Jia et al. 2009). As a result, we identified a total of seven candidate motifs (six SELEX motifs and an AC-rich element) from the ILF3 exon 18, but none from exon 19 (Fig. 6A). Subsequently, we expressed Flagtagged SRSF3 in HEK293 and analyzed Flag-SRSF3-bound host RNA transcripts by using anti-Flag CLIP 
assays (Fig. 6B). As shown in Figure 6C, total RNA extracted from the CLIPed protein-RNA complex did contain the ILF3 RNA that could be specifically detected by RT-PCR and a primer pair from exon 18 (Fig. 6C, compare lanes 8 to 7 and Fig. 6A for the primer position [arrows]), but not $\beta$-actin RNA (Fig. 6C, compare lanes 12 to 13). Sequencing of the RT-PCR product further confirmed the direct interaction between SRSF3 protein and ILF3 RNA, most likely through exon 18 (Fig. 6D).

The ILF3 exon 18 is a very large internal exon with 1351 nts and contains an alternative $3^{\prime}$ splice site that can be activated to produce the ILF3 isoform-5 RNA in U2OS and HeLa cells by knockdown of SRSF3 expression (Fig. $2 A, B)$. To ensure the SFmap predicted SRSF3-binding motifs and AC-rich elements in the ILF3 exon 18 (Fig. 6A), a series of RNA pull-down and western blotting assays were carried out by using biotinylated wild-type (wt) or mutant (mt) RNA oligos (Fig. 6E). As shown in Figure $6 \mathrm{~F}$, we demonstrated that the SFmap predicted motifs 2 and 6 are strong SRSF3-binding motifs (lane 6 on the top panel and lanes 3 and 8 in the lower panel), similar to a positive SRSF3-binding motif in HPV16 ESE (Jia et al. 2009) (lane 3 on the top panel and lane 5 in the lower panel). Motifs 1 and 3 are weaker SRSF3-binding motifs (lanes 5 and 7 on the top panel), whereas motifs 4, 5 (lanes 8 and 9 on the top panel) and 7 (lane 4 in the lower panel) do not bind SRSF3 as seen for all mutant motifs (lane 10 for motif 5 mutant on the top panel) and two motif 6 mutants (lanes 9,10 in the lower panel). HPV16 ESE mutant served as a negative control for the RNA pull-down and showed a much weaker binding to SRSF3 when compared to its wild-type ESE (lane 4 on the top panel and lane 6 in the lower panel). These data provide convincing evidence that these SRSF3-binding motifs could play a role presumably in regulation of inclusion or exclusion of the ILF3 exon 18.

\section{The characterized SRSF3-binding motifs regulate exon 18 inclusion in ILF3 RNA splicing}

To elucidate the functional relevance of the identified SRSF3-binding motifs in the ILF3 exon 18, various ILF3 minigene expression vectors under control by a cytomegalovirus IE promoter were constructed to contain the ILF3 genes from exon 16 to exon 19, with or without deletion of individual SRSF3-binding motifs in exon 18 (Fig. 7A). By using a vector-specific primer (oJR51) in combination with an exon 18 (oJR66) or exon 19 primer (oJR45) (Fig. 7A; Supplemental Table S4), we could distinguish these minigene-specific ILF3 transcripts from the endogenous ILF3 in U2OS cells and examine only the RNA splicing profile of the minigene transcripts. We found that, although all ILF3 minigene transcripts displayed a similar splicing profile of ILF3 isoform-1, the ILF3 isoform-2 splicing to include exon 18 in these minigene transcripts was found to depend on the SRSF3-binding motifs in exon 18 (Fig. 7B) and SRSF3 in U2OS cells (Supplemental Fig. S7). In general, the wt ILF3 minigene transcripts in $\mathrm{U} 2 \mathrm{OS}$ cells displayed $38 \%$ inclusion of exon 18 (Fig. 7B, lane 3) in U2OS cells, but this inclusion rate in the mt ILF3 minigene transcripts was decreased to $21 \%$ by deletion of the SRSF3-binding motifs 1-2 (Fig. 7B, lane 4) and to only $6 \%$ by deletion of the SRSF3-binding motif 6 (Fig. 7B, lane 6). As expected, decreased inclusion of exon 18 during ILF3 RNA splicing was accompanied by accumulation of the unspliced transcripts (Fig. 7B, lanes 4 and 6). In contrast, deletion of the SRSF3-binding motifs 3-4 enhanced the exon 18 inclusion rate to $59 \%$ from wt $38 \%$ (Fig. 7B, compare lane 5 with lane 3) and deletion of the SRSF3-binding motifs 1-4 increased the inclusion rate further to 94\% (Fig. 7B, compare lane 7 with lane 3). Moreover, knockdown of SRSF3 expression in U2OS cells also led to induce an ILF3 isoform-5 RNA splicing from the wt minigene transcripts (Supplemental Fig. S7) as we have seen for the SRSF3 knockdowninduced production of endogenous ILF3 isoform-5 (Fig. 2A,B). Together, these findings conclude that SRSF3 plays an essential role in inclusion of 
A

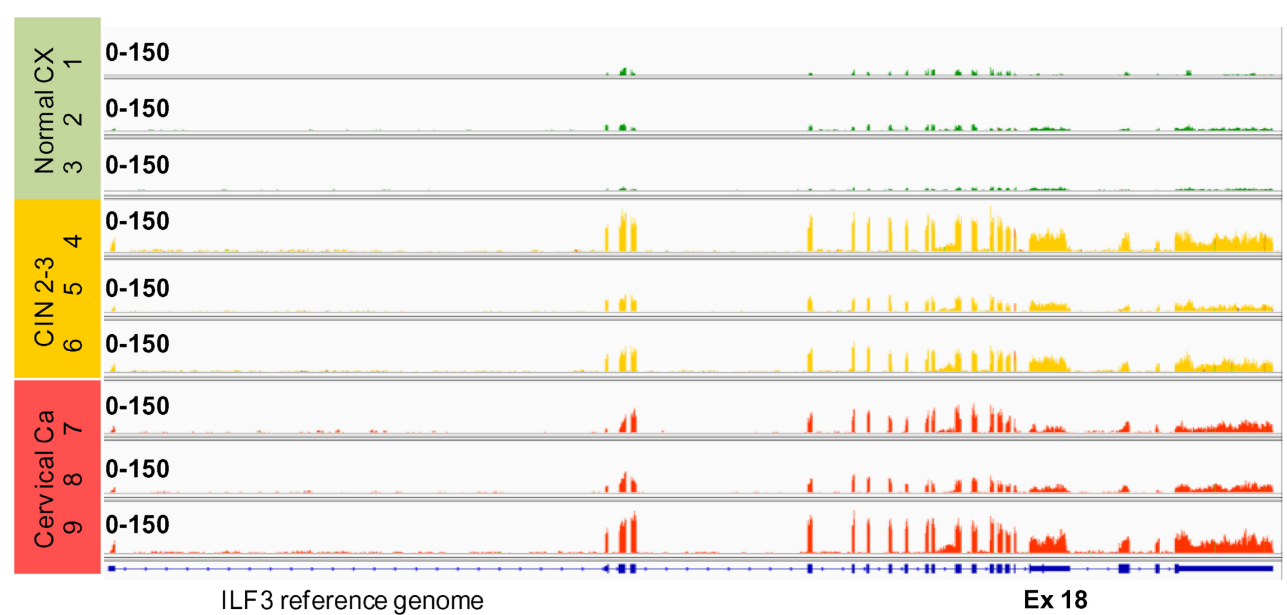

B

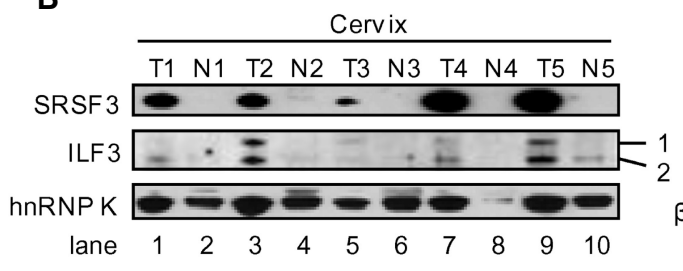

C

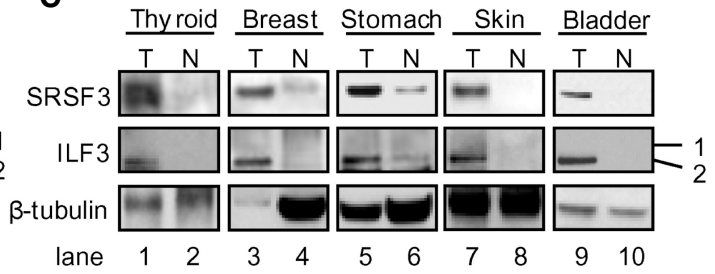

D
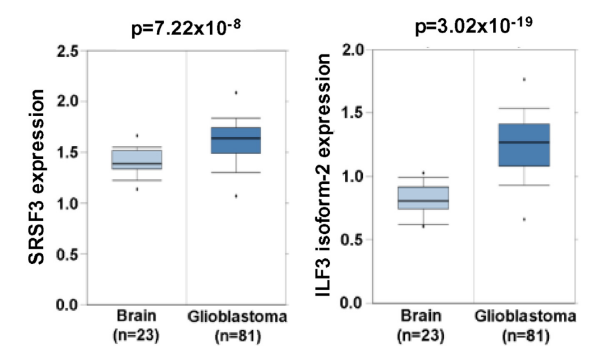

$\mathbf{E}$

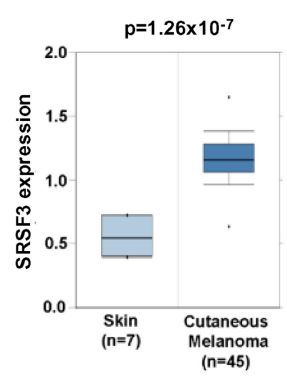

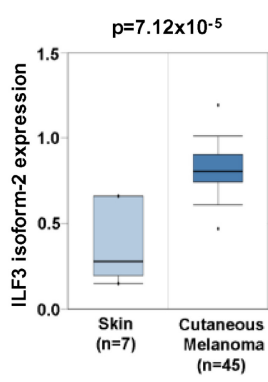

$\mathbf{F}$

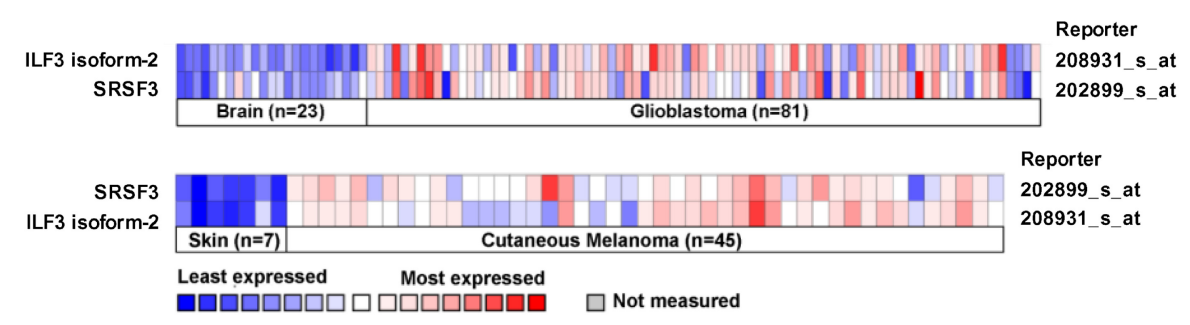

FIGURE 5. Co-upregulation of SRSF3 and ILF3 in tumor tissues. (A) RNA-seq gene expression profiling of ILF3 in normal and diseased cervical tissues. Reads coverage maps showing the RNA expression levels of ILF3 in three normal cervical tissues (green 1, 2, and 3), three cervical intraepithelial neoplasia (CIN, precancer lesion) (yellow 4, 5, and 6), and three cervical cancer tissues (red 7, 8, and 9), along with ILF3 transcript structure, were visualized by IGV. The scales (0-150) show the coverage depth of RNA reads for all samples. (B,C) Protein expression of SRSF3 and ILF3 were analyzed by western blot for tumor $(\mathrm{T})$ and normal $(\mathrm{N})$ tissues from cervix $(B)$ or thyroid, breast, stomach, skin, and bladder (C). Western blot membranes analyzed in our previous study (Jia et al. 2010) were reprobed with anti-ILF3 antibody. hnRNP K or $\beta$-tubulin served as a loading control. $(D, E)$ Co-upregulation of SRSF3 and ILF3 mRNAs in glioblastoma (D) and melanoma (E) tissues. Box plot data shown in normalized expression units were compiled from Oncomine cancer database (www.oncomine.org) from Sun's report on glioblastoma (Sun et al. 2006) and Talantov's report on melanoma (Talantov et al. 2005). (F) Heat maps show co-upregulation of ILF3 isoform-2 and SRSF3 mRNA in individual normal or cancer tissues described in $D$ and $E$ and detected by the indicated probe set (reporter). 


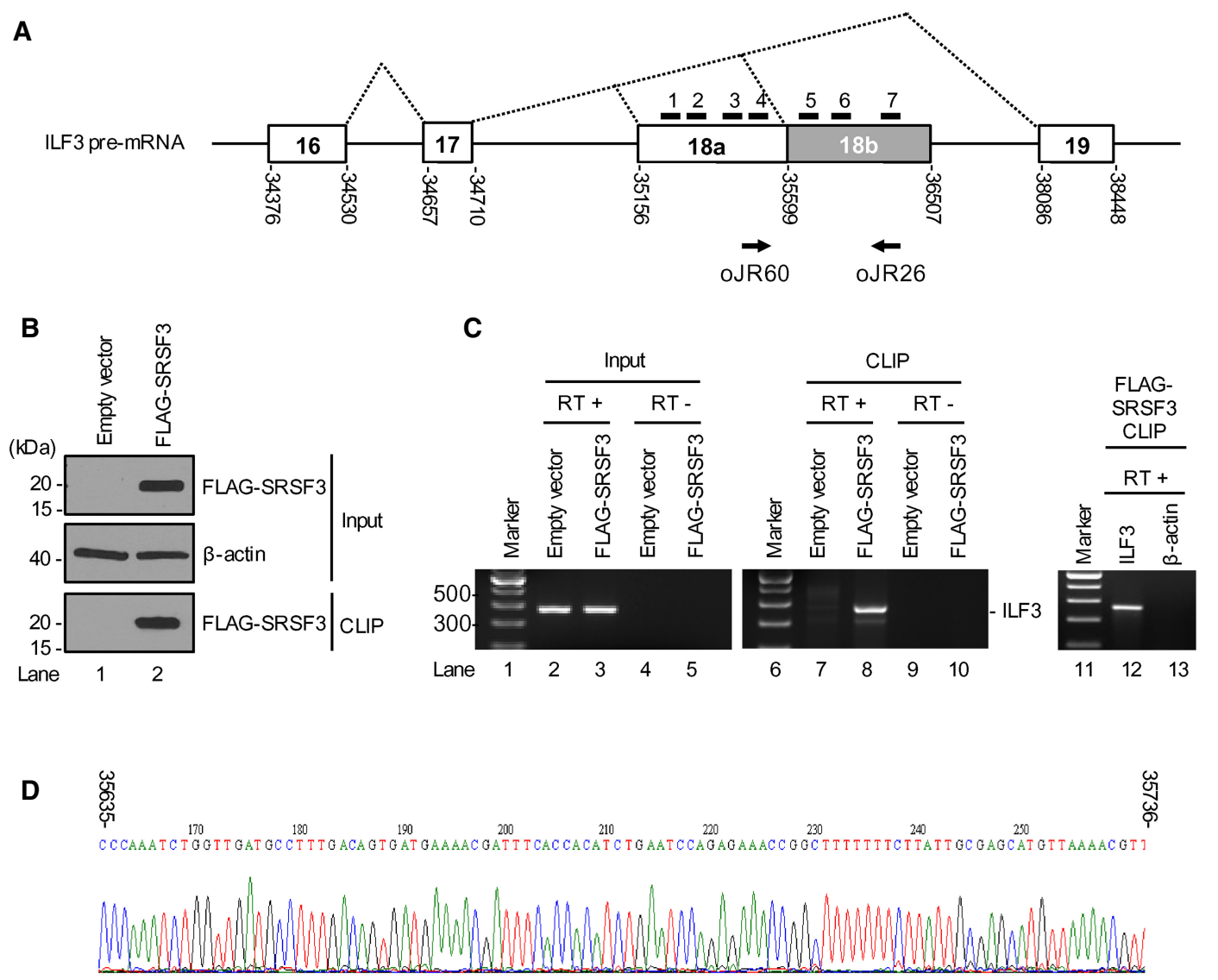

\section{E}

HPV16 ESE wt HPV16 ESE $\mathrm{mt}$ Motif 1 (35192-211) Motif 2 (35231-57) Motif $3(35307-26)$ Motif 4 (35331-50 Motif 5 (35672-61)

Motif $5 \mathrm{mt}$

Motif 6 (35770-94)

Motif $6 \mathrm{mt}-1$

Motif $6 \mathrm{mt}-2$

Motif 7 (36453-73)

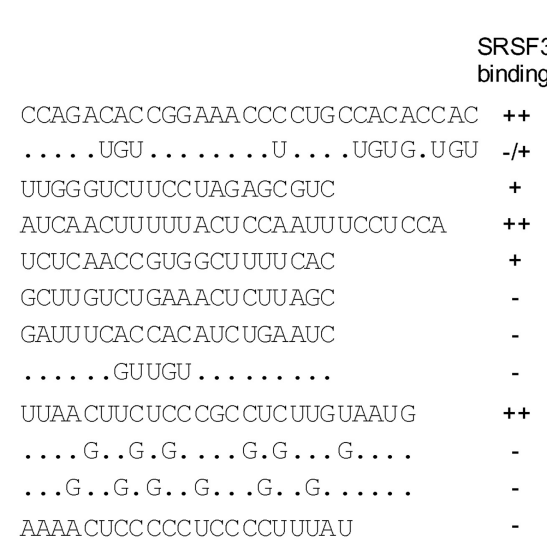

F
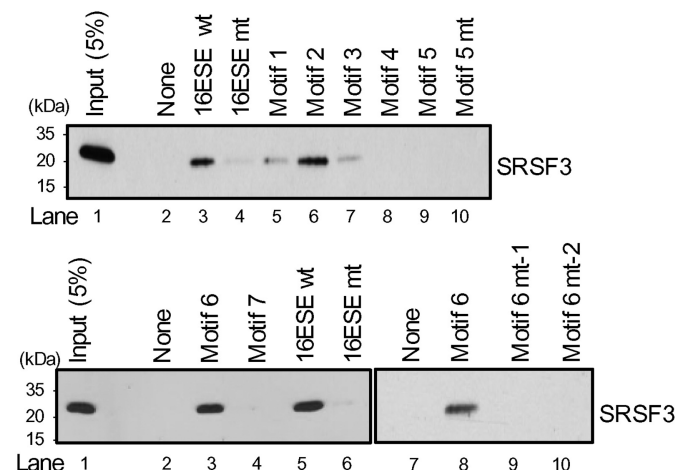

FIGURE 6. Identification of SRSF3-binding motifs in the ILF3 exon 18. (A) Diagram of the ILF3 pre-mRNA from exon 16 to exon 19 , with nt positions being numbered according to a NCBI ILF3 reference sequence (GenBank accession \# NG_029220). Relative nucleoside positions of the predicted SRSF3-binding motifs 1-7 and two PCR primers are diagrammed either above or below exon 18. (B-D) ILF3 is an RNA target for SRSF3 binding in cells. After $48 \mathrm{~h}$ transfection of Flag-SRSF3 expression vector (pMA 50), HEK293 cells were UV-crosslinked and the cell lysate was prepared for anti-Flag immunoprecipitation (IP). Specific precipitation of Flag-SRSF3 was confirmed by anti-Flag western blot (B). Total RNA extracted from input lysates and the IP products after proteinase K digestion of the cell extracts was used for ILF3 (lanes $2-5,7-10,12)$ or $\beta$-actin (lane 13) RNA detection by RT-PCR with a primer pair of oJR 60 and oJR 26 for ILF3 or oLLY381 and oLLY382 for $\beta$-actin (C). RT, reverse transcriptase. The ILF3 transcript specifically amplified in lane 8 was gel-purified and sequenced as shown in D for the CLIPed exon 18 sequences of ILF3. (E) Nucleotide positions of the predicted SRSF3-binding RNA motifs within exon 18 of ILF3. Wild-type and mutant HPV16 ESEs (Jia et al. 2009) were used as positive and negative controls for SRSF3 binding. In the mutant (mt) motifs, dots indicate the same nts as in its wt, with only mutated nt shown. Affinity to SRSF3 binding determined in our study are (++) for strong, (+) for weak, and (-) for no binding. (F) RNA pull-down assay for the predicted SRSF3-binding RNA motifs. 5'-biotin-labeled RNA of predicted SRSF3-binding motifs (1-7) were incubated with the in vitro splicing-qualified HEK293 nuclear extracts, and pull-down products were analyzed for associated SRSF3 protein by western blot by using an anti-SRSF3 antibody. Input, 5\% of HEK293 nuclear extracts. None, avidin beads only for the pull-down. 
A

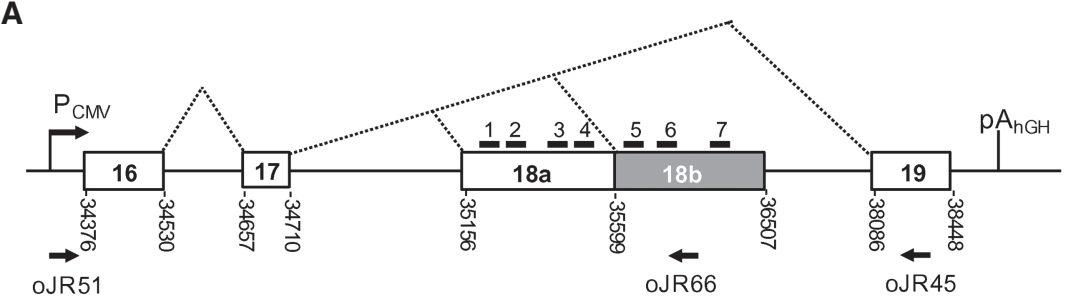

ILF3 (16-19) wt

ILF3 (16-19) $\Delta 1-2$

ILF3 (16-19) $\Delta 3-4$

ILF3 (16-19) $\Delta 6$

ILF3 (16-19) $\Delta 1-4$
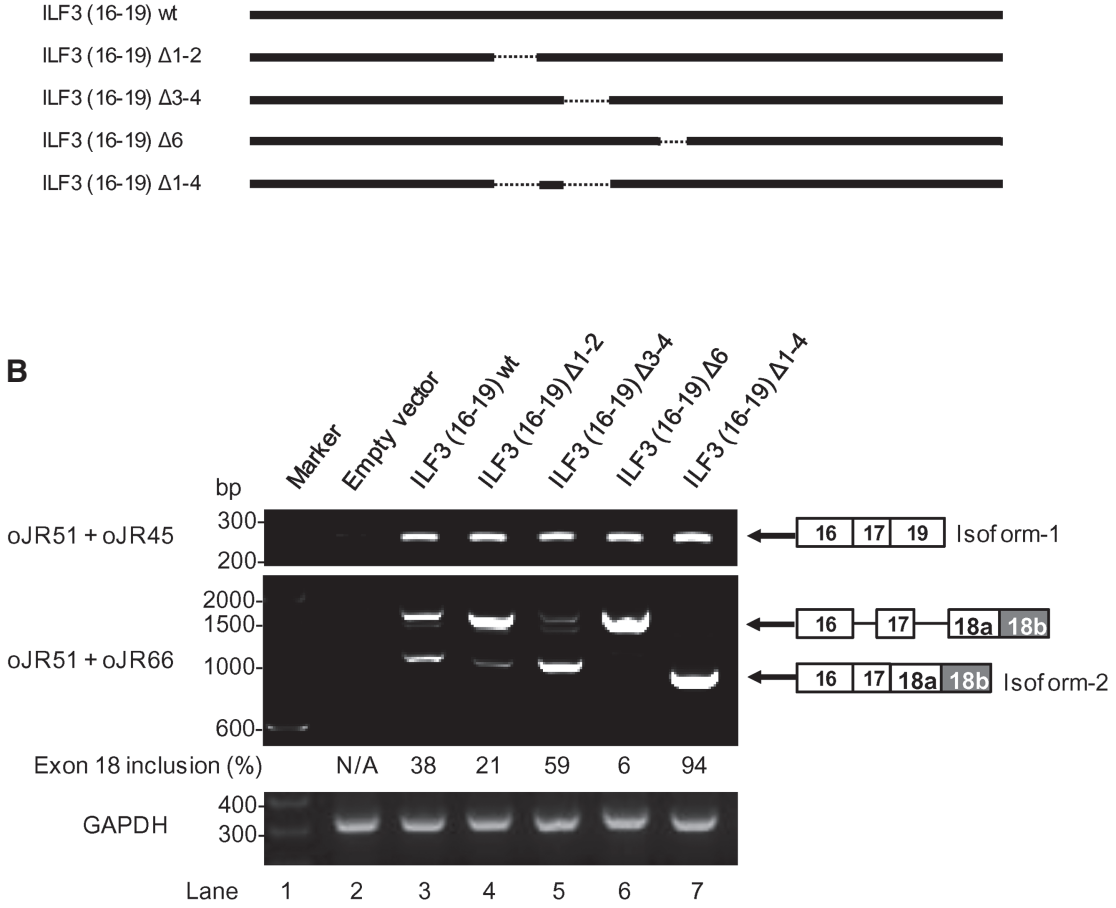

FIGURE 7. Functional requirement of SRSF3-binding motifs in regulation of ILF3 exon 18 splicing. (A) Diagram of an ILF3 minigene from exon 16 to19 in plasmid pJR8. Nucleotide positions are the NCBI genomic ILF3 reference sequence (GenBank accession \# NG_029220). The following deletion mutants were constructed for ILF3 minigene: $\Delta 1-2$, deletion of $\mathrm{nt}$ 35183-35254 to exclude putative SRSF3-binding motifs $1-2 ; \Delta 3-4$, deletion of nt 3530035357 to exclude motifs $3-4 ; \Delta 6$, deletion of nt 35770-35794 to exclude motif $6 ; \Delta 1-4$, deletion of $\mathrm{nt}$ 35183-35254 and 35300-35357 to exclude motifs 1-4. $\mathrm{pA}_{\mathrm{hGH}}$, human growth hormone $(\mathrm{hGH})$ polyadenylation signal in the vector. Arrows indicate the oligo primers used in RT-PCR, with oJR51 being a vector-specific primer. (B) Alternative RNA splicing profile of ILF3 expressed from wild-type and mutant $(\Delta 1-2, \Delta 3-4, \Delta 6$, and $\Delta 1-4)$ minigenes. U2OS cells transfected with each corresponding minigene vector and examined after $24 \mathrm{~h}$ transfection for alternative ILF3 RNA splicing by RT-PCR. Splicing efficiency (\%) of exons $17^{\wedge} 18$ was calculated and is shown below the gels. Identities of each splicing product were confirmed by sequencing. GAPDH served as RNA loading controls.

exon 18 to produce ILF3 isoform-2 during ILF3 RNA splicing via its SRSF3-binding motifs.

\section{DISCUSSION}

SRSF3 affects a global change of gene expression to maintain cell homeostasis. We recently reported that SRSF3 knockdown in a human osteosarcoma cell line (U2OS cells) regulates the expression of at least 224 coding genes and $\sim 20$ miRNAs (Ajiro et al. 2016a). Most of them are involved in cell cycle or proliferation. In this study, we provide the evidence that ectopic SRSF3 expression in mouse fibroblast MEF3T3 cells regulates 134 gene splicing events and 11 gene expressions. Among these altered changes in RNA splicing and gene expression, IIf3 and Pabpc4 transcripts were two notable targets for SRSF3.

Characterization of SRSF3-regulated ILF3 splicing led us to identify eight isoforms of human ILF3 RNA and six isoforms of mouse IIf3 RNA. The SRSF3-regulated ILF3 alternative splicing appears independently of the other three SR-rich splicing factors SRSF1, RBM5, and RBM39. Although SRSF3 and SRSF1 are mutually regulated by each other (Ajiro et al. 2016a), siRNA knockdown of SRSF1 had no effect on ILF3 splicing. However, we did find, as expected, that siRNA knockdown of RBM5 and RBM39 reduced ILF3 isoform-2 splicing. RBM39 (also called CAPER $\alpha$ or $\mathrm{HCC} 1$ ) is a member of the U2AF protein family and interacts with U2AF65 to regulate RNA splicing (Loerch and Kielkopf, 2016; Mai et al. 2016). The enrichment of RBM5 in the exon regions and its RNA-binding motifs (UCAUC and AGUAA) resembles that of SRSF3 (Änkö et al. 2012; Bechara et al. 2013; Ajiro et al. 2016a). These observations have raised the possibility that SRSF3 and RBM5 may have similar downstream RNA targets for regulated RNA splicing. In this study, we did not find SRSF3 regulation on RBM5 and RBM39 expression.

We revealed that ILF3 functions in cell transformation, and ILF3 isoform2 is more potent than ILF3 isoform-1 in promoting cell growth and transformation. We also found that cancer cell lines and human diploid lung fibroblasts with reduced ILF3 isoform-1 and -2 proliferate slowly. Consistent with this, cancer tissues obtained from cervix, thyroid, breast, stomach, skin, and bladder express much more ILF3 than their normal corresponding tissues, as has also been reported in melanoma and renal cancers (http://www.proteinatlas .org/ENSG00000129351-ILF3/pathology). In supporting these observations, other studies recently showed that MDA-MB-435 breast cancer cells with ILF3 isoform-2 (DRBP7/NF90) depletion exhibit reduced tumorigenesis 
in nude mice (Vumbaca et al. 2008), and ILF3 promotes breast tumor progression by regulating sustained urokinase-type plasminogen activator expression ( $\mathrm{Hu}$ et al. 2013). Altogether, the tumorigenic characteristics of ILF3 isoform-1/2 in our study identify ILF3 as a novel protooncogene.

Although cancer cells express isoform- 1 and mostly isoform-2 of ILF3 to promote cell proliferation by enhancing cell cycle progression to the $\mathrm{S}$ and $\mathrm{G} 2 / \mathrm{M}$ phase, other isoforms of ILF3 resulting from alternative RNA splicing can be remarkably induced when SRSF3 expression was forced to reduction by RNAi. These inducible ILF3 isoforms are isoform-5, -7, and -8. ILF3 isoform-7 and -8 are two novel isoforms that have not been described and are under detection levels in general in both normal or cancer tissues. Thus, the increased expression of ILF3 isoform-1 and -2 in cancer tissues is not at the expense of ILF3 isoform-7 and -8. Notably, we characterized ILF3 isoform-5 and -7 as cell proliferation suppressors, in sharp contrast to the cell growth promotion of ILF3 isoform-1 and -2 (Fig. 8). Although little is known about how isoform-5 func-

\section{A}

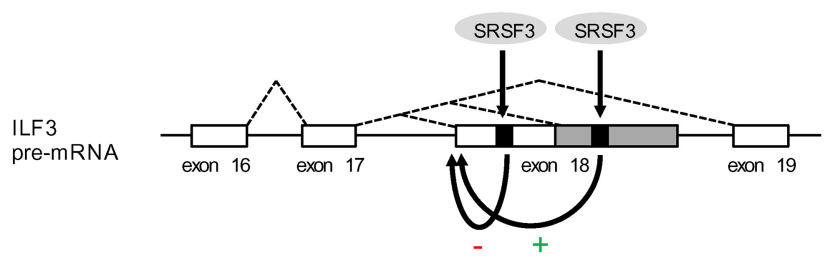

B

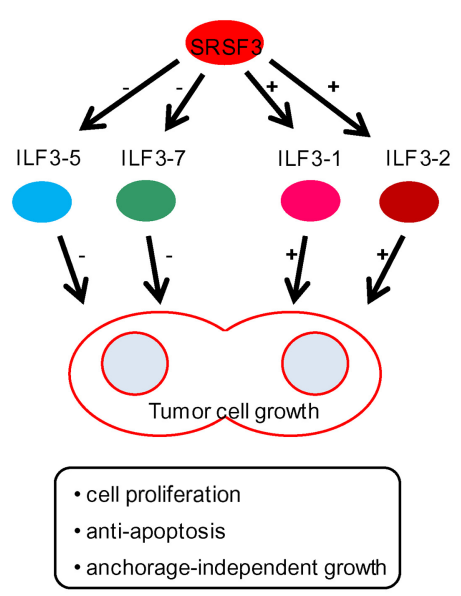

FIGURE 8. Proposed model for the SRSF3 function in production of ILF3 isoforms. (A) Exon 18 inclusion is regulated by the SRSF3-binding motifs (black boxes in exon 18) that bind to SRSF3. (B) Alternative exclusion or inclusion of exon 18 due to altered SRSF3 expression results in the production of major ILF3 isoform-1 or -2 , which promotes cell proliferation and anchorage-independent growth. SRSF3 knockdown or deletion of SRSF3-binding motifs activates alternative 3' splice sites in exon 18 for production of ILF3 isoform- 5 or promotes skipping of both exons 18 and 19 for production of ILF3 isoform-7, of which both suppress cell growth. tions, our data indicate that isoform-7 suppresses cell growth by inducing apoptosis. Because cancer cells with SRSF3 knockdown also undergo apoptosis and growth retardation (Jia et al. 2010) and exhibit decreased expression of ILF3 isoform-1 and -2 and increased expression of isoform -5 and -7 in this study, our data suggest that the effects of SRSF3 on ILF3 gene expression and alternative RNA splicing are one of the mechanisms by which SRSF3 regulates cell proliferation and oncogenesis (Fig. 8).

Similar to many SRSF3 targeted RNA splicing events, SRSF3 regulates RNA splicing of ILF3 primarily by binding to several SRSF3-binding motifs in an alternative exon, exon 18 of ILF3 (Fig. 7). Exclusion or inclusion of exon 18 during ILF3 RNA splicing is a major alternative splicing event for production of ILF3 isoform-1 (exclusion) or isoform-2 (inclusion). We demonstrated that the SRSF3-binding motifs 1, 2, and 6 are responsible for SRSF3-mediated exon 18 inclusion, and the SRSF3-binding motif 3 is required for SRSF3-mediated exon 18 exclusion. Deletion of binding motifs 1, 2, and 6 prevents RNA splicing from the ILF3 exon 17 to exon 18. In contrast, deletion of the SRSF3-binding motif 3 promotes the ILF3 exon 18 inclusion and enhances production of the ILF3 isoform-2. Consistent with these data, cancer cells and tissues express high levels of both SRSF3 and ILF3 to ensure a proportional production of ILF3 isoform-1 and isoform-2 for cancer cell growth. Thus, our study paves an important step forward in understanding how SRSF3 contributes to tumorigenesis and tumor maintenance.

\section{MATERIALS AND METHODS}

\section{Cell cultures, stable cell lines, and plasmids}

Immortal rodent fibroblast NIH 3T3 and MEF 3 T3 tet-off cells (Clontech) and human U2OS, HeLa, WI-38, and MRC-5 cells were grown in Dulbecco modified Eagle medium (DMEM, Invitrogen) supplemented with $10 \%$ fetal bovine serum (FBS) or calf serum (HyClone), $2 \mathrm{mM}$ L-glutamine, $100 \mathrm{U} / \mathrm{mL}$ penicillin, and $100 \mu \mathrm{g} / \mathrm{mL}$ streptomycin (Invitrogen). NIH 3T3 cells were transfected with pCMV6-ILF3 (isoform-1), pJR19 (ILF3 isoform2), or pSB21 (an empty pCMV-Flag vector control) and were selected with $400 \mu \mathrm{g} / \mathrm{mL}$ G418 for stable transfection. MEF 3T3 tet-off cells were transfected with plasmid pJR17 by Lipofectamine 2000 (Invitrogen), and selected with $200 \mu \mathrm{g} / \mathrm{mL}$ hygromycin and $1 \mu \mathrm{g} / \mathrm{mL}$ doxycycline for stable transfection to express T7-SRSF3 (SRp20). A cell line stably transfected with empty vector pRevTRE was also established as a control. To induce T7-SRSF3 expression, cells were grown in regular DMEM in the presence of $600 \mu \mathrm{g} / \mathrm{mL}$ hygromycin B, $100 \mu \mathrm{g} / \mathrm{mL}$ G418 without doxycycline during cell passage. Note: T7-SRSR3 will be expressed with one more passage in the absence of doxycycline, but will disappear within three to four passages in this culture even in the absence of doxycycline.

Plasmid pCMV6-ILF3 (isoform-1) that contains a full length of human ILF3 ORF (NM_012218) fused with a carboxy-terminal 
Myc-Flag tag (31 aa) was obtained from Origene. Plasmids pJR15, pJR16, pJR18, and pJR19, derived from pCMV6-ILF3 (isoform-1), were constructed to encode ILF3 isoform-8, $-7,-5$, and -2 , respectively. T7-SRp20 was swapped from pCG-T7-SRp20 expression vector (Javier Caceres) to pRevTRE, in which T7-SRp20 was under control by tetracycline, resulting in plasmid pJR17. Plasmid pMA50 (Tang et al. 2013) has a SRSF3 coding region derived from pJR7, which is inserted at EcoRI and BamHI sites at p3xFlag-CMV-14 vector. Human HeLa genomic DNA fragment from ILF3 exon 16 to exon 19 was amplified and cloned into pFlag-CMV5.1 (Sigma), resulting in the plasmid pJR8 under control by a CMV IE promoter. The corresponding deletion mutant ILF3 minigenes of individual SRSF3-binding motifs were made from plasmid pJR8 by overlapping PCR and named accordingly in Figure 7A.

\section{Cellular localization of ILF3 isoform proteins and fluorescence microscopy}

U2OS cells were transfected with pCMV6-ILF3 (isoform-1), pJR15 (isoform-8), pJR16 (isoform-7), pJR18 (isoform-5), and pJR19 (isoform-2) in the presence of lipofectamine 3000, respectively. Cells were fixed by $4 \%$ paraformaldehyde. The expression of Flagtagged ILF3 isoform proteins was analyzed by an immunochemical staining kit (Dako) with mouse monoclonal anti-Flag antibody (Sigma) and then Alexa Fluor 488 labeled goat anti-mouse IgG antibody (Thermofisher). The nucleus was stained with DAPI. Fluorescence images were collected with an Olympus FV1200 Confocal Microscope at various exposure times suited to the individual protein expression levels displayed by cells within a particular sample and saved in TIFF format. Adobe Photoshop was used to arrange processed images into composite figures.

\section{Tissue lysate, cell transfection, and western blot}

Tissue lysates of various paired tumor and matched normal tissues from different organs were purchased from Protein Biotechnologies (Ramona).

U2OS cells were transfected twice in a 48-h interval with $2 \mu \mathrm{g}$ of individual ILF3 isoform-expressing vector or in a combination in a total of $4 \mu \mathrm{g}$ plasmid DNA supplemented with an empty vector in each transfection. The cell numbers were counted and the cell lysates were prepared on day 4 after the first transfection. WI-38 and mouse NIH3T3 or MEF3T3 cells at $1 \times 10^{5}$ were seeded in each well of a 12-well plate and transfected twice in a 48-h interval by lipofectamine-mediated reverse transfection of $1 \mu \mathrm{g}$ of individual ILF3 isoform expressing vector or in combination in a total of 2 $\mu \mathrm{g}$ plasmid DNA supplemented with empty vector. The cells at 48 $h$ posttransfection were trypsinized for $20 \mathrm{sec}$ and transfected immediately with the same set of the plasmids. The cell numbers were counted and the cell lysates were prepared at day 4 after the first transfection.

For protein size profiling of ILF3 isoforms, U2OS cells were transiently transfected with plasmid pCMV6-ILF3 (isoform-1), pJR16 (isoform-7), pJR15 (isoform-8), or a combination of both pJR16 and pJR15. All ectopically expressed, Myc + Flag-tagged ILF3 protein isoforms were immunoblotted with anti-ILF3 or anti-Myc antibody at $48 \mathrm{~h}$ after transfection.
Protein samples in $2 \times$ SDS sample buffer were denatured by boiling for $5 \mathrm{~min}$, separated by NuPAGE Bis-Tris gel electrophoresis (Invitrogen), transferred onto a nitrocellulose membrane, and blotted with the following antibodies: mouse monoclonal antibodies against SRSF3 (7B4, ATCC), $\beta$-tubulin (BD PharMingen), $\beta$-actin (Sigma), hnRNP K (D-6, Santa Cruz Biotech), Flag tag (Sigma), Myc tag (Santa Cruz Biotech), and PARP (Calbiochem), or rabbit antibody against ILF3 (Aviva).

\section{RNAi and cell growth rescuing experiment}

SRSF3, SRSF1, RBM5, RBM39, and ILF3 siRNAs were purchased from Dharmacon as a siGenome SMARTpool (human SFRS3, cat. no. M-030081-00; human SRSF1, cat. no. M-018672-01; human ILF3, cat. no. M-012442-01). Nonspecific (NS) siRNA from Dharmacon has 52\% GC content (cat. no. D-001206-08-20). RNAi was conducted by two separate transfections, at an interval of $48 \mathrm{~h}$, with $40 \mathrm{nM}$ of siRNA in the presence of Lipofectamine 3000 as described. The cells with knockdown of the indicated gene expression were then analyzed for cell count and growth rate by trypan blue exclusion, cell cycle by flow cytometry, RNA splicing by RT-PCR, RNA transcript expression by TaqMan RTqPCR, and protein expression by western blotting with a specific antibody.

To rescue cell growth, U2OS cells at $4 \times 10^{4}$ per well in a 24-well plate were cotransfected twice with $40 \mathrm{nM}$ of SRSF3-specific siRNA or nonspecific (NS) siRNA and 500 ng of a Flag-tagged ILF3 isoform-2 expression plasmid (ILF3-2) or control plasmid (Vector) in a $48 \mathrm{~h}$ interval in the presence of lipofectamine 3000. Transfected cells were divided into four groups: ILF3-2 + SRSF3 siRNA, ILF3-2 + NS siRNA, Vector + SRSF3 siRNA, and Vector + NS siRNA. Cell numbers were counted at day 2 and day 4 after transfection. Expression of Flag-tagged ILF3 isoform-2 and knockdown efficiency of SRSF3 expression were verified by western blot using a mouse monoclonal anti-Flag, anti-SRSF3, or anti$\beta$-actin antibody.

\section{RNA preparation and RT-PCR}

Total cell RNA was prepared from the cells using TRIzol (Invitrogen) following the manufacturer's instructions. Following DNase I treatment, $1 \mu \mathrm{g}$ of RNA was reverse transcribed at $42^{\circ} \mathrm{C}$ using random hexamers and then amplified using gene-specific primer pairs (Supplemental Table S4) as in the following: oJR44 and oJR45 for ILF3 isoform-1; oJR24 and oJR26 for ILF3 isoform-2 and -5; oJR44 and oJR52 for ILF3 isoform-7 and -8; oJR44 and oJR118 for mouse Ilf3 isoform-1; oJR115 and oJR116 for mouse IIf3 isoform-2; oJR44 and oJR 52 for mouse IIf3 isoform-3; oLLY379 and oLLY380 for IIf3 exon 3 skipping; oJR51 and oJR26, oJR45 or oJR66 for ectopic ILF3 from plasmid pJR8; oLLY176 and oLLY177 for mouse Pabpc4; oLLY381 and oLLY382 for human $\beta$-actin; oZMZ269 and oZMZ270 for human GAPDH; oMA1 and oMA2 for mouse Gapdh.

RT-qPCR for detection of RBM5 and RBM39 was carried out by using commercially available gene-specific TagMan probes (RBM5 assay no. Hs01554570_m1; RBM39 assay no. Hs00863 502_g1 ThermoFisher Scientific). 


\section{Colony formation assay}

NIH3T3 cells stably transfected with stable expression of ILF3 isoform-1 (pCMV6-ILF3), ILF3 isoform-2 (pJR19), or control vector (pSB21) were harvested, adjusted to $1 \times 10^{4}$ cells in DMEM containing $0.35 \%$ of agar and $10 \%$ FBS, and subsequently laid onto a bottom layer containing $0.5 \%$ agar and 10\% FBS in DMEM in a six-well plate. The plates at 2 wk later were stained by $0.005 \%$ crystal violet for colony counting.

\section{RNA pull-down assay}

RNA pull-down assay was conducted as previously described (Ajiro et al. 2016a). Briefly, 5'-biotin labeled RNA oligos (Supplemental Table S4) were conjugated with Neurtavidin agarose (Thermo Fisher Scientific), followed by washing with TBS and overnight incubation with in vitro splicing-qualified HEK293 nuclear extracts (ProteinOne) in IP buffer $(50 \mathrm{mM}$ Tris- $\mathrm{HCl}[\mathrm{pH}$ 7.4], $1 \%$ NP-40, $0.25 \%$ deoxycholate, $150 \mathrm{mM} \mathrm{NaCl}, 10 \%$, glycerol, $1 \mathrm{mM}$ EDTA, and 0.5 mM EGTA). RNA-bound proteins were eluted with $2 \times$ Laemmli buffer, followed by washing four times. Eluted proteins were analyzed by western blot.

\section{Cross-linking and immunoprecipitation (CLIP) coupled with RT-PCR}

CLIP RT-PCR was performed as described previously (Majerciak et al. 2006; Kang et al. 2011; Tang et al. 2013) to detect SRSF3bound endogenous ILF3 RNA. HEK293 cells were transfected with pMA50 (SRSF3 with a carboxy-terminal 3xFlag) (Tang et al. 2013), or an empty vector p3xFlag-CMV-14 (Sigma Aldrich), followed by UV-crosslinking by $480 \mathrm{~mJ} 48 \mathrm{~h}$ after the transfection. UV-crosslinked cells were then collected with IP buffer $(50 \mathrm{mM}$ Tris- $\mathrm{HCl}[\mathrm{pH} 7.4], 1 \%$ NP-40, 0.25\% deoxycholate, $150 \mathrm{mM}$ $\mathrm{NaCl}, 10 \%$, glycerol). IP was performed with anti-Flag (M2) affinity gel (Sigma), and immunoprecipitation products were then treated with $0.2 \mathrm{mg} / \mathrm{mL}$ proteinase $\mathrm{K}$ for $30 \mathrm{~min}$ at $37^{\circ} \mathrm{C}$. Precipitated total RNA was extracted with phenol/chloroform/isoamylalcohol extraction, treated with TURBO DNase (Ambion) for $30 \mathrm{~min}$ at $37^{\circ} \mathrm{C}$, and applied for RT-PCR reaction with a random hexamer.

\section{Splicing microarray analysis}

MEF3T3 tet-off cells were transfected with pRevTRE/T7-SRSF3 expression vector (pJR17) or pFlag-CMV5.1 empty vector, each performed in triplicate. Fifty nanograms of total RNA isolated from the MEF3T3 cells with or without human SRSF3 overexpression was quality controlled, and a mouse genome-wide splice-array assay was performed by using service provider ExonHit Therapeutics, Inc. (Ajiro et al. 2016a).

\section{RNA-seq data analysis}

The RNA-seq data (NCBI GSE113942) from our previous study (Xu et al. 2019) were mapped to human reference genome (hg19, GRCh37). Coverage and distribution of ILF3-specific reads along with the annotated ILF3 transcripts were visualized by the Integrative Genomics Viewer (IGV, Broad Institute) program.

\section{Oncomine cancer microarray database analyses}

The Oncomine cancer microarray database (http://www .oncomine.com) was used to analyze expression profiles of SRSF3 and ILF3 in a variety of human cancer and normal tissues. Statistics from individual studies were also obtained from the Oncomine cancer database. Overexpression of SRSF3 or ILF3 isoform-2 are defined as their expression levels significantly higher $(P<0.05)$ in tumor tissues than in their corresponding normal tissues. Because ILF3 expresses multiple RNA isoforms and any given array platform may use multiple probes to detect the expression of different ILF3 isoforms, we specified a specific probe, based on available probe sequences in a given study, for detection of ILF3 isoform-2 expression.

\section{Statistical analysis}

Unpaired two-tailed Student's t-test was used to compare the differences in cell counts between indicated groups. The same method was also used to compare the differences between two groups, including tumor sizes and tumor weights. Statistical data in paired microarray data sets in each study were obtained directly from the Oncomine cancer database (www.oncomine .org).

\section{SUPPLEMENTAL MATERIAL}

Supplemental material is available for this article.

\section{ACKNOWLEDGMENTS}

This research was supported by the Intramural Research Program of the Center for Cancer Research at the National Cancer Institute, National Institutes of Health (1ZIASC010357 to Z.M.Z.) and a Japanese Society for the Promotion of Science Fellowship (to M.A.).

Author contributions: J.R. contributed all initial mouse splicearray experiments and characterization of ILF3 and drafted the partial manuscript. M.A. identified and characterized SRSF3-binding motifs in ILF3 RNA and drafted the partial manuscript. L.Y. identified SRSF3 overexpression on alternative splicing of mouse Pabpc4 RNA and IIf3 exon 3 skipping, and human RBM5 and RBM39 expression, RNA-seq analysis, partial SRSF3 CLIP assays, and SRSF1, RBM5, and RBM39 on ILF3 splicing and isoform production. J.P.M. contributed the FACS analysis. Z.M.Z. designed and oversaw the study, analyzed all data, drafted, and finalized the manuscript. All authors approved the final version of this manuscript.

Received September 3, 2018; accepted February 21, 2019

\section{REFERENCES}

Ajiro M, Jia R, Yang Y, Zhu J, Zheng ZM. 2016a. A genome landscape of SRSF3-regulated splicing events and gene expression in human osteosarcoma U2OS cells. Nucleic Acids Res 44: 1854-1870. doi:10.1093/nar/gkv1500

Ajiro M, Tang S, Doorbar J, Zheng ZM. 2016b. Serine/arginine-rich splicing factor 3 and heterogeneous nuclear ribonucleoprotein 
A1 regulate alternative RNA splicing and gene expression of human papillomavirus 18 through two functionally distinguishable cis elements. J Virol 90: 9138-9152. doi:10.1128/JVI.00965-16

Akerman M, David-Eden H, Pinter RY, Mandel-Gutfreund Y. 2009. A computational approach for genome-wide mapping of splicing factor binding sites. Genome Biol 10: R30. doi:10.1186/gb2009-10-3-r30

Änkö ML, Müller-McNicoll M, Brandl H, Curk T, Gorup C, Henry I, Ule J, Neugebauer KM. 2012. The RNA-binding landscapes of two SR proteins reveal unique functions and binding to diverse RNA classes. Genome Biol 13: R17. doi:10.1186/gb-2012-13-3r17

Ayane M, Preuss U, Köhler G, Nielsen PJ. 1991. A differentially expressed murine RNA encoding a protein with similarities to two types of nucleic acid binding motifs. Nucleic Acids Res 19: 1273-1278. doi:10.1093/nar/19.6.1273

Barber GN. 2009. The NFAR's (nuclear factors associated with dsRNA): evolutionarily conserved members of the dsRNA binding protein family. RNA Biol 6: 35-39. doi:10.4161/rna.6.1.7565

Bechara EG, Sebestyén E, Bernardis I, Eyras E, Valcárcel J. 2013. $\mathrm{RBM} 5,6$, and 10 differentially regulate NUMB alternative splicing to control cancer cell proliferation. Mol Cell 52: 720-733. doi:10 .1016/j.molcel.2013.11.010

Bedard KM, Daijogo S, Semler BL. 2007. A nucleo-cytoplasmic SR protein functions in viral IRES-mediated translation initiation. EMBO J 26: 459-467. doi:10.1038/sj.emboj.7601494

Buaas FW, Lee K, Edelhoff SE, Disteche C, Braun RE. 1999. Cloning and characterization of the mouse interleukin enhancer binding factor 3 (IIf3) homolog in a screen for RNA binding proteins. Mamm Genome 10: 451-456. doi:10.1007/s003359901022

Busch A, Hertel KJ. 2012. Evolution of SR protein and hnRNP splicing regulatory factors. Wiley. Interdiscip Rev RNA 3: 1-12. doi:10 $.1002 /$ wrna.100

Castella S, Bernard R, Corno M, Fradin A, Larcher JC. 2015. IIf3 and NF90 functions in RNA biology. Wiley Interdiscip Rev RNA 6: 243-256. doi:10.1002/wrna.1270

Cavaloc Y, Bourgeois CF, Kister L, Stévenin J. 1999. The splicing factors $9 \mathrm{G} 8$ and SRp20 transactivate splicing through different and specific enhancers. RNA 5: 468-483. doi:10.1017/ S1355838299981967

Christofk HR, Vander Heiden MG, Harris MH, Ramanathan A, Gerszten RE, Wei R, Fleming MD, Schreiber SL, Cantley LC. 2008. The M2 splice isoform of pyruvate kinase is important for cancer metabolism and tumour growth. Nature 452: 230-233. doi:10.1038/nature06734

Cooper TA, Wan L, Dreyfuss G. 2009. RNA and disease. Cell 136: 777-793. doi:10.1016/j.cell.2009.02.011

Cui M, Allen MA, Larsen A, Macmorris M, Han M, Blumenthal T. 2008. Genes involved in pre-mRNA $3^{\prime}$-end formation and transcription termination revealed by a lin-15 operon Muv suppressor screen. Proc Natl Acad Sci 105: 16665-16670. doi:10.1073/pnas .0807104105

Duchange N, Pidoux J, Camus E, Sauvaget D. 2000. Alternative splicing in the human interleukin enhancer binding factor 3 (ILF3) gene. Gene 261: 345-353. doi:10.1016/S0378-1119(00)00495-9

Dvinge H, Kim E, Abdel-Wahab O, Bradley RK. 2016. RNA splicing factors as oncoproteins and tumour suppressors. Nat Rev Cancer 16: 413-430. doi:10.1038/nrc.2016.51

Grosso AR, Martins S, Carmo-Fonseca M. 2008. The emerging role of splicing factors in cancer. EMBO Rep 9: 1087-1093. doi:10.1038/ embor.2008.189

Guan D, tan-Bonnet N, Parrott AM, Arrigo CJ, Li Q, Khaleduzzaman M, Li H, Lee CG, Pe'ery T, Mathews MB. 2008. Nuclear factor 45 (NF45) is a regulatory subunit of complexes with
NF90/110 involved in mitotic control. Mol Cell Biol 28: 46294641. doi:10.1128/MCB.00120-08

Hargous Y, Hautbergue GM, Tintaru AM, Skrisovska L, Golovanov AP, Stevenin J, Lian LY, Wilson SA, Allain FH. 2006. Molecular basis of RNA recognition and TAP binding by the SR proteins SRp20 and 9G8. EMBO J 25: 5126-5137. doi:10.1038/sj.emboj.7601385

Hautbergue GM, Hung ML, Golovanov AP, Lian LY, Wilson SA. 2008. Mutually exclusive interactions drive handover of mRNA from export adaptors to TAP. Proc Natl Acad Sci 105: 5154-5159. doi:10.1073/pnas.0709167105

Heinzen EL, Ge D, Cronin KD, Maia JM, Shianna KV, Gabriel WN, Welsh-Bohmer KA, Hulette CM, Denny TN, Goldstein DB. 2008. Tissue-specific genetic control of splicing: implications for the study of complex traits. PLoS Biol 6: e1. doi:10.1371/journal .pbio. 1000001

Hu Q, Lu YY, Noh H, Hong S, Dong Z, Ding HF, Su SB, Huang S. 2013. Interleukin enhancer-binding factor 3 promotes breast tumor progression by regulating sustained urokinase-type plasminogen activator expression. Oncogene 32: 3933-3943. doi:10.1038/onc .2012 .414

Huang Y, Gattoni R, Stévenin J, Steitz JA. 2003. SR splicing factors serve as adapter proteins for TAP-dependent mRNA export. Mol Cell 11: 837-843. doi:10.1016/S1097-2765(03)00089-3

Hui J, Hung LH, Heiner M, Schreiner S, Neumüller N, Reither G, Haas SA, Bindereif A. 2005. Intronic CA-repeat and CA-rich elements: a new class of regulators of mammalian alternative splicing. EMBO J 24: 1988-1998. doi:10.1038/sj.emboj.7600677

Jia R, Liu X, Tao M, Kruhlak M, Guo M, Meyers C, Baker CC, Zheng ZM. 2009. Control of the papillomavirus early-to-late switch by differentially expressed SRp20. J Virol 83: 167-180. doi:10 .1128/JVI.01719-08

Jia R, Li C, McCoy JP, Deng CX, Zheng ZM. 2010. SRp20 is a protooncogene critical for cell proliferation and tumor induction and maintenance. Int J Biol Sci 6: 806-826. doi:10.7150/ijbs.6.806

Kang JG, Pripuzova N, Majerciak V, Kruhlak M, Le SY, Zheng ZM. 2011. Kaposi's sarcoma-associated herpesvirus ORF57 promotes escape of viral and human interleukin-6 from microRNA-mediated suppression. J Virol 85: 2620-2630. doi:10.1128/JVI.02144-10

Kuwano Y, Kim HH, Abdelmohsen K, Pullmann R, Martindale JL Jr, Yang X, Gorospe M. 2008. MKP-1 mRNA stabilization and translational control by RNA-binding proteins HuR and NF90. Mol Cell Biol 28: 4562-4575. doi:10.1128/MCB.00165-08

Loerch S, Kielkopf CL. 2016. Unmasking the U2AF homology motif family: a bona fide protein-protein interaction motif in disguise. RNA 22: 1795-1807. doi:10.1261/rna.057950.116

Long JC, Caceres JF. 2009. The SR protein family of splicing factors: master regulators of gene expression. Biochem J 417: 15-27. doi:10.1042/BJ20081501

Lou H, Neugebauer KM, Gagel RF, Berget SM. 1998. Regulation of alternative polyadenylation by U1 snRNPs and SRp20. Mol Cell Biol 18: 4977-4985. doi:10.1128/MCB.18.9.4977

Mai S, Qu X, Li P, Ma Q, Cao C, Liu X. 2016. Global regulation of alternative RNA splicing by the SR-rich protein RBM39. Biochim Biophys Acta 1859: 1014-1024. doi:10.1016/j.bbagrm.2016.06 .007

Majerciak V, Yamanegi K, Nie SH, Zheng ZM. 2006. Structural and functional analyses of Kaposi sarcoma-associated herpesvirus ORF57 nuclear localization signals in living cells. J Biol Chem 281: 28365-28378. doi:10.1074/jbc.M603095200

Majerciak V, Kruhlak M, Dagur PK, McCoy JP Jr, Zheng ZM. 2010. Caspase-7 cleavage of Kaposi sarcoma-associated herpesvirus ORF57 confers a cellular function against viral lytic gene expression. J Biol Chem 285: 11297-11307. doi:10.1074/jbc.M109 .068221 
Patiño C, Haenni AL, Urcuqui-Inchima S. 2015. NF90 isoforms, a new family of cellular proteins involved in viral replication? Biochimie 108: 20-24. doi:10.1016/j.biochi.2014.10.022

Paz I, Akerman M, Dror I, Kosti I, Mandel-Gutfreund Y. 2010. SFmap: a web server for motif analysis and prediction of splicing factor binding sites. Nucleic Acids Res 38: W281-W285. doi:10.1093/nar/ gkq444

Pei Y, Zhu P, Dang Y, Wu J, Yang X, Wan B, Liu JO, Yi Q, Yu L. 2008. Nuclear export of NF90 to stabilize IL-2 mRNA is mediated by AKT-dependent phosphorylation at $\mathrm{Ser}^{647}$ in response to CD28 costimulation. J Immunol 180: 222-229. doi:10.4049/jimmunol .180 .1 .222

Pfeifer I, Elsby R, Fernandez M, Faria PA, Nussenzveig DR, Lossos IS, Fontoura BM, Martin WD, Barber GN. 2008. NFAR-1 and -2 modulate translation and are required for efficient host defense. Proc Natl Acad Sci 105: 4173-4178. doi:10.1073/pnas.0711222105

Reichman TW, Mathews MB. 2003. RNA binding and intramolecular interactions modulate the regulation of gene expression by nuclear factor 110. RNA 9: 543-554. doi:10.1261/rna.2181103

Reichman TW, Parrott AM, Fierro-Monti I, Caron DJ, Kao PN, Lee CG, $\mathrm{Li} \mathrm{H}$, Mathews MB. 2003. Selective regulation of gene expression by nuclear factor 110, a member of the NF90 family of doublestranded RNA-binding proteins. J Mol Biol 332: 85-98. doi:10 .1016/S0022-2836(03)00885-4

Saunders LR, Jurecic V, Barber GN. 2001a. The 90- and 110-kDa human NFAR proteins are translated from two differentially spliced mRNAs encoded on chromosome 19p13. Genomics 71: 256259. doi:10.1006/geno.2000.6423

Saunders LR, Perkins DJ, Balachandran S, Michaels R, Ford R, Mayeda A, Barber GN. 2001b. Characterization of two evolutionarily conserved, alternatively spliced nuclear phosphoproteins, NFAR-1 and -2, that function in mRNA processing and interact with the double-stranded RNA-dependent protein kinase, PKR. J Biol Chem 276: 32300-32312. doi:10.1074/jbc.M104207200

Shamanna RA, Hoque M, Pe'ery T, Mathews MB. 2013. Induction of p53, p21 and apoptosis by silencing the NF90/NF45 complex in human papilloma virus-transformed cervical carcinoma cells. Oncogene 32: 5176-5185. doi:10.1038/onc.2012.533

Shi L, Zhao G, Qiu D, Godfrey WR, Vogel H, Rando TA, Hu H, Kao PN. 2005. NF90 regulates cell cycle exit and terminal myogenic differentiation by direct binding to the $3^{\prime}$-untranslated region of MyoD and p21 WAF1/CIP1 mRNAs. J Biol Chem 280: 18981-18989. doi:10 .1074/jbc.M411034200

Shi L, Godfrey WR, Lin J, Zhao G, Kao PN. 2007. NF90 regulates inducible IL-2 gene expression in T cells. J Exp Med 204: 971977. doi:10.1084/jem.20052078

Sun L, Hui AM, Su Q, Vortmeyer A, Kotliarov Y, Pastorino S, Passaniti A, Menon J, Walling J, Bailey R, et al. 2006. Neuronal and glioma-derived stem cell factor induces angiogenesis within the brain. Cancer Cell 9: 287-300. doi:10.1016/j.ccr.2006.03.003

Talantov D, Mazumder A, Yu JX, Briggs T, Jiang Y, Backus J, Atkins D, Wang Y. 2005. Novel genes associated with malignant melanoma but not benign melanocytic lesions. Clin Cancer Res 11: 72347242. doi:10.1158/1078-0432.CCR-05-0683

Tang Y, Horikawa I, Ajiro M, Robles Al, Fujita K, Mondal AM, Stauffer JK, Zheng ZM, Harris CC. 2013. Downregulation of splicing factor SRSF3 induces p53 $\beta$, an alternatively spliced isoform of p53 that promotes cellular senescence. Oncogene 32: 27922798. doi:10.1038/onc.2012.288

Tewari M, Quan LT, O'Rourke K, Desnoyers S, Zeng Z, Beidler DR, Poirier GG, Salvesen GS, Dixit VM. 1995. Yama/CPP32 $\beta$, a mammalian homolog of CED-3, is a CrmA-inhibitable protease that cleaves the death substrate poly(ADP-ribose) polymerase. Cell 81: 801-809. doi:10.1016/0092-8674(95)90541-3

Urcuqui-Inchima S, Castaño ME, Hernandez-Verdun D, StLaurent G III, Kumar A. 2006. Nuclear Factor 90, a cellular dsRNA binding protein inhibits the HIV Rev-export function. Retrovirology 3: 83. doi:10.1186/1742-4690-3-83

Viranaicken W, Gasmi L, Chauvin C, Denoulet P, Larcher JC. 2006. Identification of a newly spliced exon in the mouse Ilf3 gene generating two long and short isoforms of $11 \mathrm{f3}$ and NF90. Genomics 88: 622-632. doi:10.1016/j.ygeno.2006.08.006

Vumbaca F, Phoenix KN, Rodriguez-Pinto D, Han DK, Claffey KP. 2008. Double-stranded RNA-binding protein regulates vascular endothelial growth factor mRNA stability, translation, and breast cancer angiogenesis. Mol Cell Biol 28: 772-783. doi:10.1128/ MCB.02078-06

Wang ET, Sandberg R, Luo S, Khrebtukova I, Zhang L, Mayr C, Kingsmore SF, Schroth GP, Burge CB. 2008. Alternative isoform regulation in human tissue transcriptomes. Nature 456: 470476. doi:10.1038/nature07509

$\mathrm{Xu}$ YH, Grabowski GA. 1999. Molecular cloning and characterization of a translational inhibitory protein that binds to coding sequences of human acid $\beta$-glucosidase and other mRNAs. Mol Genet Metab 68: 441-454. doi:10.1006/mgme.1999.2934

Xu YH, Leonova T, Grabowski GA. 2003. Cell cycle dependent intracellular distribution of two spliced isoforms of TCP/ILF3 proteins. Mol Genet Metab 80: 426-436. doi:10.1016/j.ymgme .2003.09.006

Xu J, Liu H, Yang Y, Wang X, Liu P, Li Y, Meyers C, Banerjee NS, Wang H-K, Cam M, et al. 2019. Genome-wide profiling of cervical RNA binding proteins identifies human papillomavirus regulation of RNASEH2A expression by viral E7 and E2F1. mBio 10: e02687-18. doi:10.1128/mBio.02687-18

Yu Y, Maroney PA, Denker JA, Zhang XH, Dybkov O, Lührmann R, Jankowsky E, Chasin LA, Nilsen TW. 2008. Dynamic regulation of alternative splicing by silencers that modulate $5^{\prime}$ splice site competition. Cell 135: 1224-1236. doi:10.1016/j.cell.2008.10.046

Zahler AM, Lane WS, Stolk JA, Roth MB. 1992. SR proteins: a conserved family of pre-mRNA splicing factors. Genes Dev 6: 837847. doi:10.1101/gad.6.5.837

Zheng ZM. 2004. Regulation of alternative RNA splicing by exon definition and exon sequences in viral and Mammalian gene expression. J Biomed Sci 11: 278-294. doi:10.1007/BF02254432 

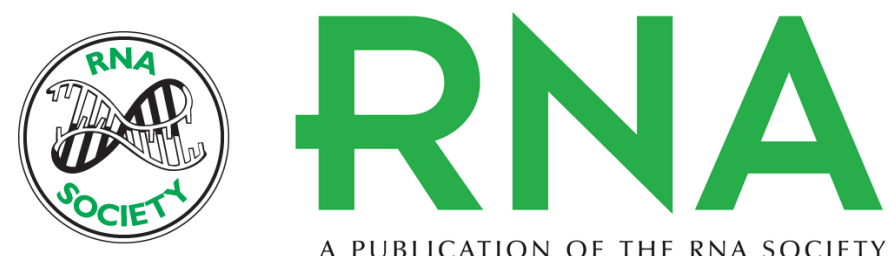

A PUBLICATION OF THE RNA SOCIETY

\section{Oncogenic splicing factor SRSF3 regulates ILF3 alternative splicing to promote cancer cell proliferation and transformation}

Rong Jia, Masahiko Ajiro, Lulu Yu, et al.

RNA 2019 25: 630-644 originally published online February 22, 2019

Access the most recent version at doi:10.1261/rna.068619.118

\section{Supplemental http://rnajournal.cshlp.org/content/suppl/2019/02/22/rna.068619.118.DC1 \\ Material}

References This article cites 60 articles, 24 of which can be accessed free at:

http://rnajournal.cshlp.org/content/25/5/630.full.html\#ref-list-1

License This is a work of the US Government.

Email Alerting Receive free email alerts when new articles cite this article - sign up in the box at the Service top right corner of the article or click here. 